\title{
CONSTITUCIÓN ECONÓMICA DE 1993 Y DESEMPEÑO ECONÓMICO EN EL PERÚ
}

\author{
ECONOMIC CONSTITUTION OF 1993 AND ECONOMIC \\ PERFORMANCE IN PERU
}

\section{Vladimir Rodríguez Cairo*}

Docente Asociado de la Facultad de Ciencias Contables, UNMSM

[Recepción: Julio de 2012/ Conformidad: Agosto 2012]

\section{RESUMEN}

Una Constitución Económica se caracteriza por consagrar reglas de juego claras en materia económica dentro de la Constitución Política de un país para un determinado tiempo de su devenir histórico. Sin embargo, un aspecto relevante que complementa ese conjunto de normas constitucionales de carácter económico es que existan mecanismos de control para el cumplimiento de las mismas.

En efecto, la regulación de los aspectos económicos en una Constitución no es una práctica que haya existido siempre en los sistemas jurídicos del mundo. La Constitución alemana de la República de Weimar de 1919 es considerada por muchos como la pionera y constituye la base del constitucionalismo económico, ya que estableció el ordenamiento jurídico fundamental de la actividad económica. Para otros, es la Carta Magna de 1215 la primera en fijar reglas de carácter económico, porque en ella se dispusieron limitaciones a la potestad tributaria del Monarca.

Actualmente, existe un mayor consenso sobre la importancia de la Constitución Económica como marco institucional que contribuye positivamente en el desempeño económico de un país.

En tal sentido, a continuación se presenta una perspectiva histórica de las principales doctrinas, los antecedentes de la Constitución Económica, la fundamentación teórica, así como el contenido y un breve análisis de las principales reglas de juego de carácter económico reguladas en la Constitución vigente de 1993, analizada dentro de su contexto histórico.

Palabras clave: Constitución Económica 1993, reglas de juego claras, desempeño económico perú

\begin{abstract}
An Economic Constitution characterized by clear rules on economic matters in the constitution of a country for a certain period of its history. However, an important aspect that complements these set of rules and constitutional economic controls the mechanisms, which should exist to fulfill them.

Indeed, the regulation of the economics in a constitution is not a practice that has always existed in the legal systems of the world. The German constitution of the Weimar Republic in 1919 is considered by many as the pioneer and is the basis of economic constitutionalism as it established of the basic law of economic activity. For others, the Constitution of 1215 is the first set of economic rules because it placed limitation of the taxing powers of the monarch.

Currently, there is a growing consensus on the importance of the Economic Constitution and its institutional framework that contributes positively to the economic performance of a country. In this regard, the following is a historical perspective of the major doctrines, a history of economic constitution (theoretical as well as the content), and a brief analysis of the main rules of the economic game regulated in the current Constitution of 1993, analyzed within its historical context.
\end{abstract}

Keywords: Economic Constitution 1993, clear rules, economic performance 


\section{PERSPECTIVA HISTÓRICA DE LAS PRINCIPALES DOCTRINAS ECONÓ- MICAS}

Douglass North (1993: 169) sostiene que la finalidad de la historia económica ${ }^{1}$ es tratar de explicar las diversas pautas de crecimiento, estancamiento y descomposición de las sociedades a lo largo del tiempo, y explorar la forma en que las fricciones, que son consecuencia de la interacción humana, producen resultados enormemente divergentes.

\section{Diagrama N.o 01 :}

Finalidades de la historia económica

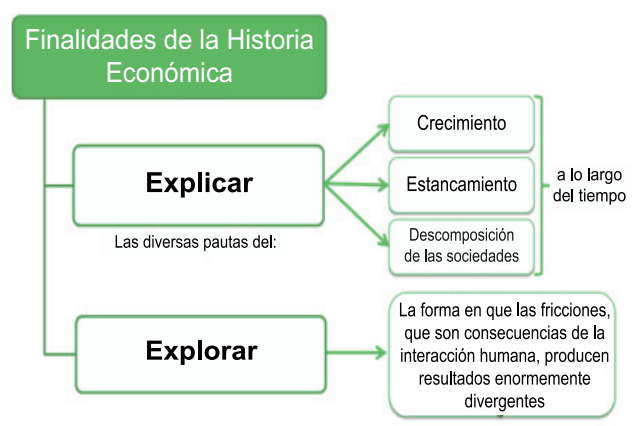

Evidentemente, no se recrea el pasado, se construye historias y relatos sobre el pasado. En el siguiente diagrama se puede apreciar la perspectiva histórica de las principales doctrinas económicas ${ }^{2}$. En él se puede notar la evolución del pensamiento económico y a la vez, el contexto político en el que se dieron.

\section{Diagrama N.o 02: \\ Perspectiva histórica de las principales doctrinas económicas}

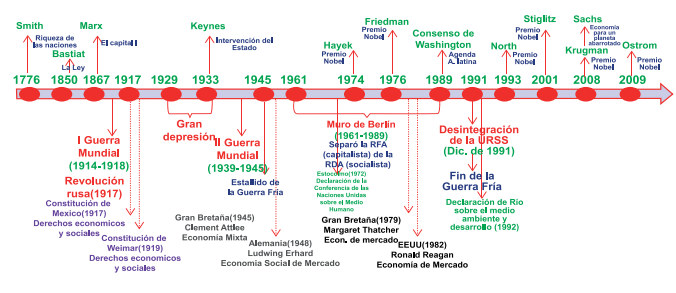

Un aspecto trascendente dentro de la historia del pensamiento económico fue la Gran Depresión. Sobre este hecho, Paul Krugman ${ }^{3}$ (2009: 109-10) afirma que en diciembre de 1930 , cuando comenzaba a ser obvio que no se trataba de una recesión normal, J.M. Keynes ${ }^{4}$ intentó explicar al público las causas de la crisis en general: "Tenemos problemas con el alternador". Estaba afirmando que el motor económico no arrancaría por su propia cuenta y que necesitaba un empujón por parte del gobierno. Keynes consideraba que el

1 Para Marx dos son los elementos que constituyen la base sociológica de su análisis económico: la interpretación económica de la historia y la teoría de clases y la lucha de las mismas (Roll 1994: 234).

2 Las doctrinas económicas son postulados filosóficos, principios y opiniones en materia económica que se han expuesto a lo largo de la historia y que sirven de fundamento a la teoría económica. Toda doctrina económica consta formalmente de tres partes: 1) supuestos o ideas básicas, derivadas de las concepciones filosóficas elaboradas o aceptadas por el autor; 2) observaciones o nociones, fruto del estudio que el autor de la doctrina ha realizado sobre el desarrollo de la vida económica; 3) reglas o normas para resolver racionalmente el problema económico o sistematizar la vida económica.

3 En el 2008 obtuvo el Premio Nóbel de Economía por sus aportaciones a la Economía Internacional, Geografía Económica y su análisis de los patrones de comercio y localización de la actividad económica. Fue crítico de las políticas económicas de George W. Bush. Sostiene que las políticas establecidas por el Fondo Monetario Internacional han sido las causantes de las crisis financieras a nivel mundial. Es así que en su obra ampliada y actualizada De vuelta a la economía de la Gran Depresión y la Crisis del 2008 explica fenómenos como la recesión, depresión, devaluaciones, inflación entre otros monstruos que rondaron la economía de los años treinta, reaparecieron a finales del siglo XX y nuevamente, a inicios del siglo XXI. Según él, en vez de improvisar teorías para resolver los nuevos problemas, hubiera bastado recurrir a los métodos keynesianos para volver a encontrar el rumbo.

4 John Maynard Keynes (1883-1946) fue un economista británico, cuyas ideas tuvieron una fuerte repercusión en las teorías económicas y políticas modernas, así como también en las políticas fiscales de muchos gobiernos. Es considerado, con juicio casi unánime, como el más reconocido economista de nuestro siglo. Ocupó diversos cargos de asesoría gubernamental y más tarde fue director del Banco de Inglaterra. Su obra central: Teoría general de la ocupación, el interés y el dinero, desafió el paradigma económico dominante al momento de su publicación en 1936. 
capitalismo $^{5}$ no estaba condenado, que una clase de intervención muy limitada, una intervención que dejaría intactas la propiedad privada y la toma de decisiones privadas, era todo lo que se necesitaba para hacer que el sistema funcionara. Paul Samuelson (19152009) denominó a este pacto como la síntesis neoclásica. Paul Krugman lo llama "acuerdo keynesiano".

Diagrama N.o 03:

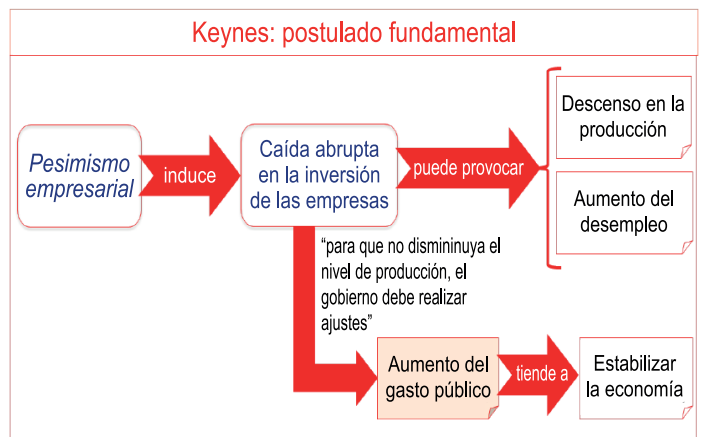

Desde tal perspectiva, la Segunda Guerra Mundial propició el empujón que Keynes había estado urgiendo durante años. Pero lo que restauró la fe en los mercados libres no fue la recuperación de la Depresión sino la seguridad de que la intervención macroeconómica (reducción de los intereses o aumento de los déficits presupuestales) podría mantener más o menos estable, y con más o menos empleo, a una economía de libre mercado.

Como resulta evidente, Keynes opinaba que la economía de mercado llegaría a cometer tropiezos y cuando éste tropezase con dificultades, los mecanismos del mercado no funcionarían, por lo tanto el gobierno debía intervenir.
Diagrama N.o 04:

\section{Keynes: intervención del gobierno}

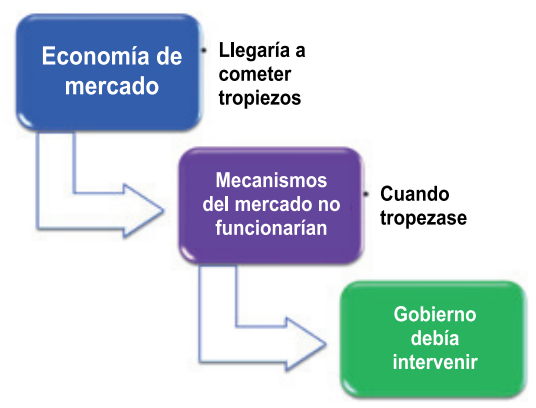

De ahí que, otro aspecto esencial de los postulados de Keynes fue que el gasto público debería ir a contracorriente, esto es, en tiempos de bonanza el gobierno debe acumular superávit fiscal y en tiempos de crisis, como la Gran Depresión, se debe aumentar el gasto público, entrar en déficit, para devolver el poder adquisitivo a los trabajadores.

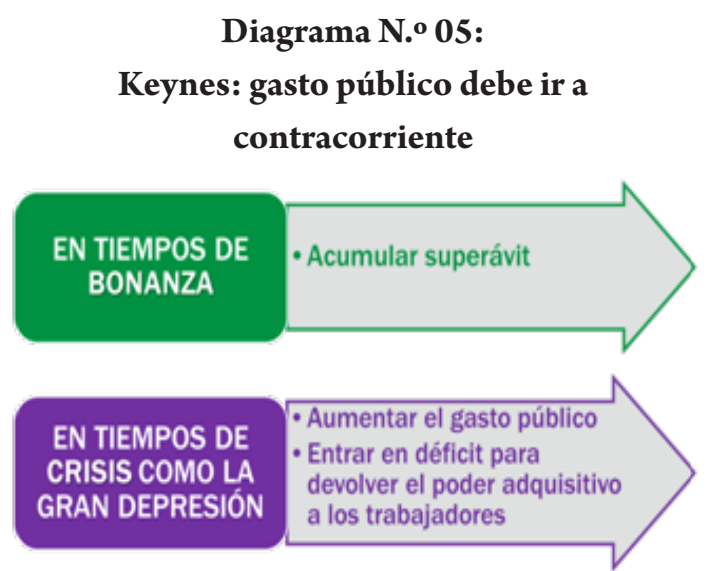

Además, es importante señalar que en los años treinta se dio una pugna ideológica entre Keynes y Hayek. Pero, fueron las ideas de Keynes las que se impusieron, con lo que Hayek perdió relevancia y mucha de la fama que había ganado de joven ${ }^{6}$.

5 Eric Roll (1994: 22) sostiene que aquella sociedad, o la más antigua descrita en el Antiguo Testamento, poseía, sin duda, algunas de las características del capitalismo moderno: propiedad privada, división del trabajo, mercados y moneda.

6 Las ideas de Hayek recobran vigencia a finales de los años setenta, cuando Margaret Thatcher asume como Primera Ministra del Reino Unido. 
Es así que en la década de 1930 surge el sistema de economía mixta ${ }^{7}$ como respuesta al colapso de las economías puras de mercado. Se sustenta en las teorías de Keynes y en la experiencia del New Deal ${ }^{8}$. Sus principales características: rectoría del Estado en la dirección del sistema económico, existencia de empresas privadas nacionales y extranjeras, áreas económicas planificadas y privatizadas, aceptación parcial y regulada del mercado, liberalización parcial del comercio exterior, protección estatal de sectores atrasados, servicios públicos en salud, seguridad social, etc., libertad individual empresarial.

Por otra parte, Friedrich Von Hayek ${ }^{9}$, (1898-1992) considerado el inspirador de la Escuela de Chicago ${ }^{10}$ y maestro reconocido por la Escuela Austriaca, fue uno de los mayores críticos de la economía planificada y socialista. Hayek (1978: 126) afirma que: "La planificación central significa que el problema económico ha de ser resuelto por la comunidad y no por el individuo". Sostiene que toda planificación económica, por leve que sea, conduce necesariamente hacia el totalitarismo y pérdida de libertades económicas. Para él la ex Unión Soviética y la Alemania Nazi son ejemplos de países que han recorrido el camino de servidumbre y llegaron a esa situación.
Diagrama N.o 06:

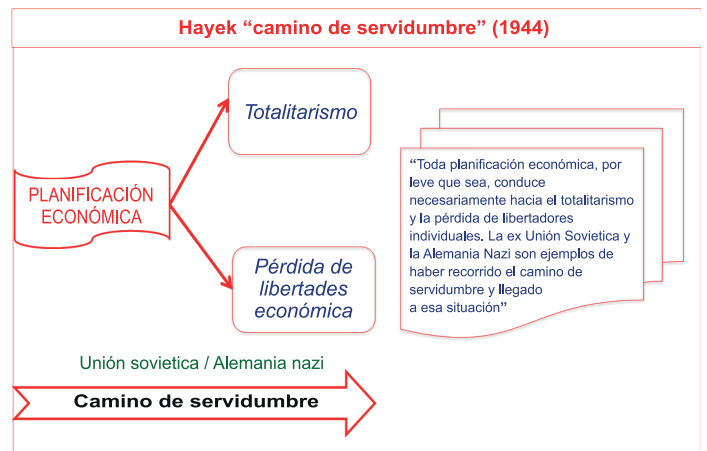

En esencia para Hayek, demasiada planificación otorga demasiado poder y esto destruye la libertad y por lo tanto, esclaviza al hombre.

\section{Diagrama N.o 07:}

\section{Hayek: Demasiada planificación destruye la libertad y esclaviza al hombre}

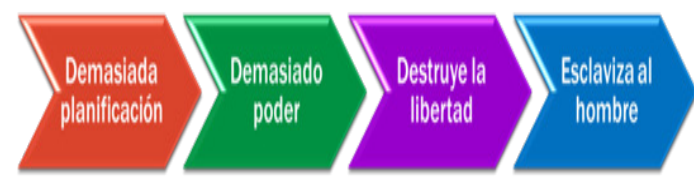

No obstante, para Hayek, la inflación ${ }^{11}$, piedra angular de su tesis, corroe la sociedad y socava la democracia ${ }^{12}$.

7 También denominado Economía Social de Mercado y jurídicamente, Estado Social de Derecho.

8 El New Deal fue el Programa de política económica puesto en práctica en los EE.UU. El Presidente F. D. Roosevelt (19331945) implantó una nueva administración y sacó al país de la crisis dotándolo de una legislación social. Puso énfasis en algunas ideas económicas que luego fueron sistematizadas por J.M. Keynes en su obra Teoría General de la Ocupación, el interés y el dinero (1936), quien sostiene que en determinadas situaciones el Estado debe intervenir para sacar a la economía de una situación de desempleo y que el gasto público debe incrementarse cuando la inversión privada no alcanza un nivel suficiente.

9 Premio Nobel de Economía en 1974, junto con Gunnar Myrdal por su trabajo pionero en la teoría del dinero y las fluctuaciones económicas, y por sus análisis de la interdependencia de los fenómenos económicos, sociales e institucionales.

10 Grupo de economistas (Henry Simons, Milton Friedman, George Stigler, Gary Becker y Arnold Harberger) que sostienen que el libre mercado y la competencia contribuirán a que el funcionamiento de la economía sea más eficiente. Postulan una intervención mínima del Estado en la economía, además, el sistema monetario tiene una importancia primordial en un país.

11 La noción moderna de la inflación es que se concibe a ésta como el aumento o crecimiento sostenido del nivel general de precios de los bienes y servicios a lo largo del tiempo, ocasionando una pérdida del poder adquisitivo. Por lo tanto, la inflación hace que el valor real del dinero se diluya con el transcurso del tiempo.

12 Documental "Batalla por la Economía Mundial” (Barker 2002). 
Diagrama N.o 08:

Hayek: inflación corre la sociedad y socava la democracia

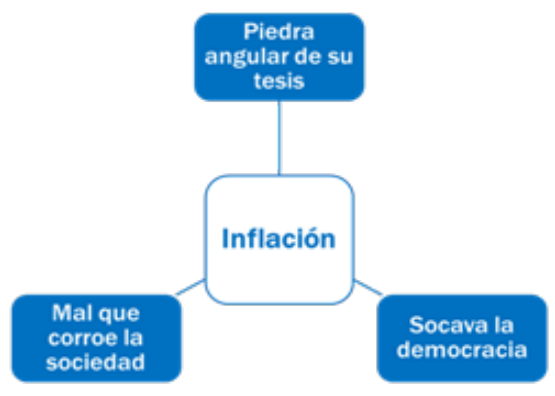

Sin lugar a dudas, Hayek postula que cualquier política encaminada de manera directa a un ideal de justicia distributiva o distribución "más justa" tiene necesariamente que conducir a la destrucción del imperio de la ley porque, para poder producir el mismo resultado en personas diferentes, sería necesario tratarlas de forma diferente.

\section{Diagrama N.o 09:}

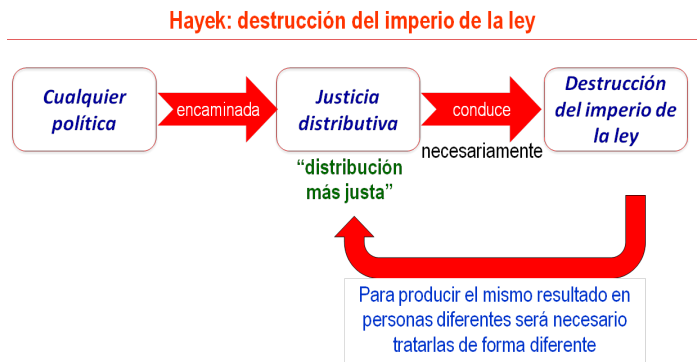

En definitiva, a lo largo del último siglo se ha venido dando un combate intelectual para determinar quién debe hacerse cargo de los puestos de mando de la economía: los go- biernos o los mercados. Los puestos de mando de la economía rusa en 1922 eran: acero, ferrocarriles, carbón, industria pesada. Por su parte, los puestos de mando de la economía británica en 1979 estaban determinados por: electricidad, teléfono, líneas aéreas, ferrocarriles, petróleo, gas, carbón, acero ${ }^{13}$.

\section{Diagrama N.o 10:}

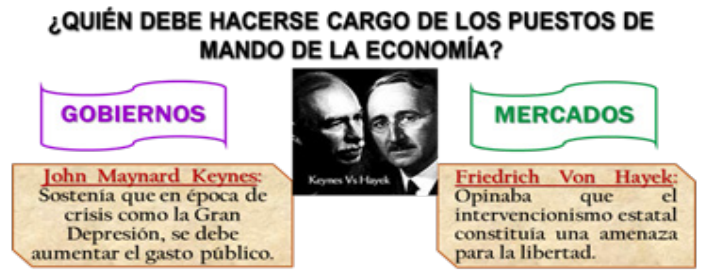

Inclusive, Harry G. Johnson ${ }^{14}$ considera que los keynesianos escogieron un mejor argumento desde el punto de vista político (el desempleo ${ }^{15}$ ) que los monetaristas ${ }^{16}$ (la inflación).

Diagrama N.o 11 :

Keynesianismo y monetaristas: punto de vista político

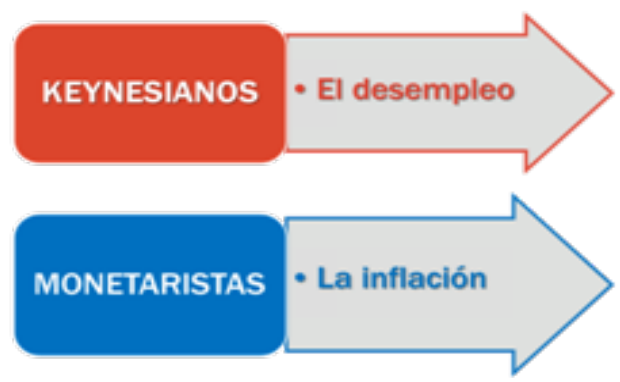

13 Documental "Batalla por la Economía Mundial" (Barker 2002).

14 Miembro de la Escuela de Chicago, escribió un análisis interesante de la revolución keynesiana y de la contrarrevolución monetarista en 1971.

15 Keynes (2003: 267) al referirse a la desocupación, afirma que el profesor Pigou cree que, a la larga, la desocupación puede remediarse por medio de ajustes de salarios; "en tanto que yo sostengo que el salario real (sujeto solamente a un límite mínimo señalado por la desutilidad marginal de la ocupación) no está determinado en primer término por los "ajustes de salarios" (aunque éstos pueden tener repercusiones), sino por las otras fuerzas del sistema, algunas de las cuales (en particular la relación entre la curva de la eficiencia marginal del capital y la tasa de interés) no las ha incluido el profesor Pigou."

16 Eric Roll (1994: 562) argumenta que en algunas escuelas de economía imbuidas de un arraigado respeto hacia las virtudes de la no intervención del Estado, como la monetarista, se nota, paradójicamente, una tendencia similar hacia una fe absoluta en el "piloto automático" de la fuente de dinero, en cuya posición "puede ser asegurada" y mantener así el navío en el curso deseado. 
Por ende, el gran debate en la era de la Depresión ${ }^{17}$ se produjo entre los conservadores fiscales, que querían contener el déficit, y los keynesianos, que pensaban que el gobierno debía incurrir en déficits para estimular la economía (Stiglitz 2010: 94).

Diagrama N.o 12:

Debate en la era de la Depresión: Keynesianos vs. Conservadores fiscales

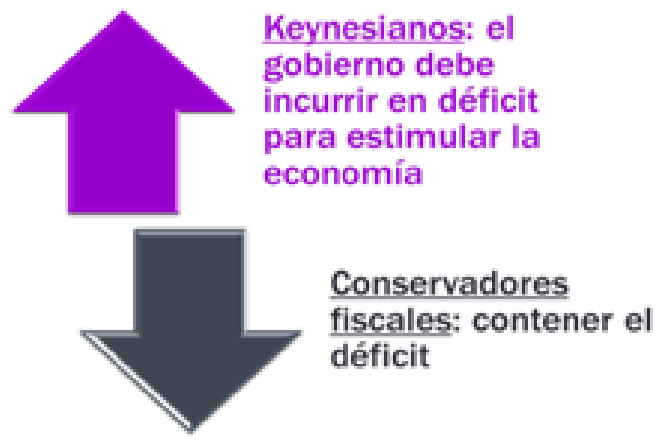

En síntesis, de acuerdo con Stiglitz ${ }^{18}$, (2010: 284) la Gran Depresión demostró que la economía de mercado no se autorregulaba, al menos en un espacio de tiempo razonable. La economía se supone que es una ciencia predictiva. Si esto es así, la teoría de la Escuela de Chicago merece un suspenso: no predijo la última crisis. Difícilmente hubiera podido hacerlo, puesto que ni las burbujas ni el desempleo existen y tuvo poco que decir sobre lo que había que hacer cuando se produjo, salvo negar los riesgos que implicaba el déficit público. Su receta es muy fácil: que el gobierno no intervenga.

\section{ESTADO SOCIAL DE DERECHO Y SURGIMIENTO DE LA CONSTITU- CIÓN ECONÓMICA}

\subsection{Estado social de derecho}

El surgimiento del Estado social de Derecho es consecuencia de la incorporación de cláusulas de contenido económico y social en las cuales se reflejaba la asignación de nuevas tareas y fines estaduales; se da a fines del siglo XIX e inicios del siglo XX. Tiene como antecedente al Estado de Derecho ${ }^{19}$. Busca acomodar la convivencia dentro de un orden económico y social con la finalidad de plasmar la justicia social y, por ende, generar una sociedad con igualdad de oportunidades.

Diagrama N.o 13:

Estado Social de Derecho
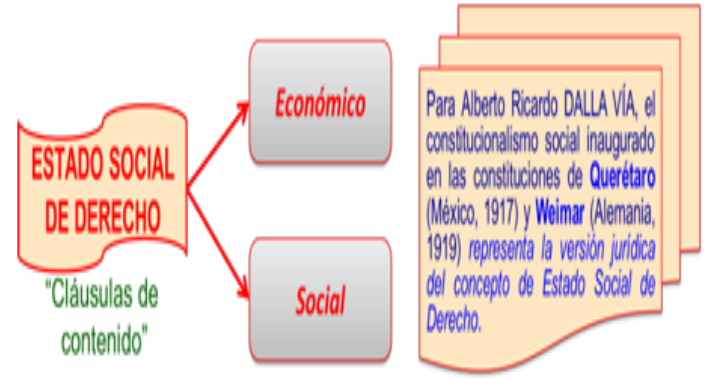

Según Víctor García (2008: 164), la expresión Estado Social de Derecho fue acuñada por Hermann Heller en su obra Teoría del Estado (1929). En efecto, para Heller el Estado Social de Derecho consistía en la viabilidad de un orden justo de la autoridad sobre la economía, particularmente sobre la limitación de la propiedad privada, subordinación del régimen laboral al derecho, intervención coercitiva del Estado en el proceso productivo y transposición de la actividad económica

17 Los años de la depresión estimularon grandemente la acumulación y el uso sistemático de estadísticas como parte central de las políticas económicas.

18 Premio Nobel de Economía en el 2001, junto con George Akerlof y Michael Spence "Por sus análisis de los mercados con información asimétrica”. Conocido por su visión crítica de la globalización, de los economistas de libre mercado (a quienes llama "fundamentalistas de libre mercado"), del Fondo Monetario Internacional y Banco Mundial.

19 Para Friedrich Von Hayek (1978: 105) Estado de Derecho significa que el Estado está sometido en todas sus acciones a normas fijas y conocidas de antemano. En otras palabras, sistema político que se sustenta en la supremacía de la ley. 
del ámbito del derecho privado al campo del interés público.

\section{Diagrama N.o 14:}

\section{Surgimiento del Estado Social de Derecho}

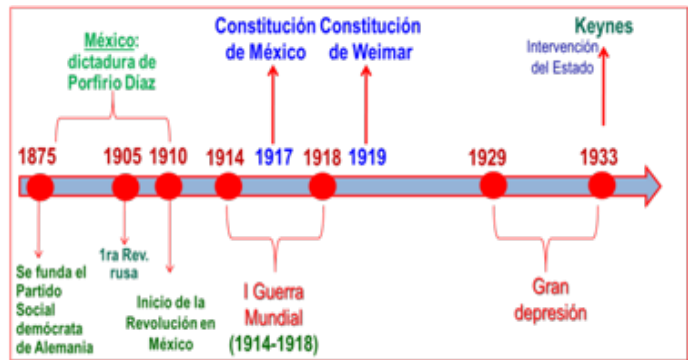

\subsection{CONSTITUCIÓN DE MÉXICO (1917) Y CONSTITUCIÓN DE WEI- MAR (1919)}

Sin duda, la incorporación del constitucionalismo social en la Constitución de Querétaro y la Constitución de Weimar generó un nuevo enfoque de Estado de Derecho. Fue en la Constitución Federal de México (1917) que se elevó a nivel constitucional los postulados de la transformación económica, política, social y cultural, y que continuó en la primera posguerra con la Constitución Alemana de Weimar $(1919)^{20}$.

\section{Diagrama N.o 15:}

\section{Constitución de México y Constitución de Weimar}

\begin{tabular}{|l|l|l|}
\hline AÑO & \multicolumn{1}{|c|}{ CONSTITUCIÓN } & \multicolumn{1}{c|}{ DERECHOS QUE PROTEGE } \\
\hline 1917 & $\begin{array}{l}\text { Constitución Federal } \\
\text { de los Estadoseterminación de los pueblos, } \\
\text { Unidos de México }\end{array}$ & $\begin{array}{l}\text { derechos laborales, igualdad, derecho a } \\
\text { la tierra, libertad de culto, enseñanza } \\
\text { laica y gratuita, jornada de trabajo de } \\
\text { ocho horas y asociación de los } \\
\text { trabajadores. }\end{array}$ \\
1919 & $\begin{array}{l}\text { Constitución de de } \\
\text { Weimar - Alemania libertad de enseñanza, enseñanza } \\
\text { obligatoria y pública, educación para la } \\
\text { reconciliación entre los pueblos, } \\
\text { derechos laborales. }\end{array}$ \\
\hline
\end{tabular}

Los derechos sociales, económicos y culturales son aquellos derechos considerados de tipo colectivo, también conocidos como derechos de segunda generación ${ }^{21}$. Constituyen una obligación de hacer del Estado y son de satisfacción progresiva de acuerdo con las posibilidades económicas del mismo.

\section{Diagrama N.o 16:}

Contenido de los derechos de segunda generación

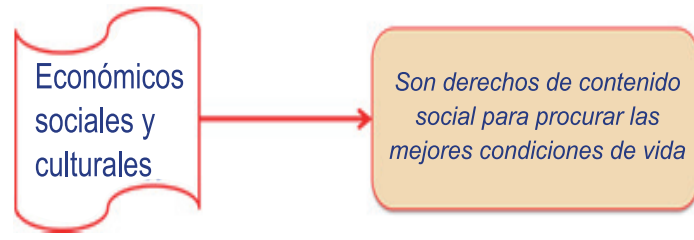

\subsection{FUNDAMENTOS DEL ESTADO SO- CIAL DE DERECHO}

De acuerdo con Víctor García ${ }^{22}$ los fundamentos del Estado Social de Derecho son:

1. La consecución de la justicia social. Entendida esta como la compenetración de la justicia legal y distributiva. Apunta a una más armoniosa regulación del binomio sociedad e individuo.

Diagrama N.o 17:

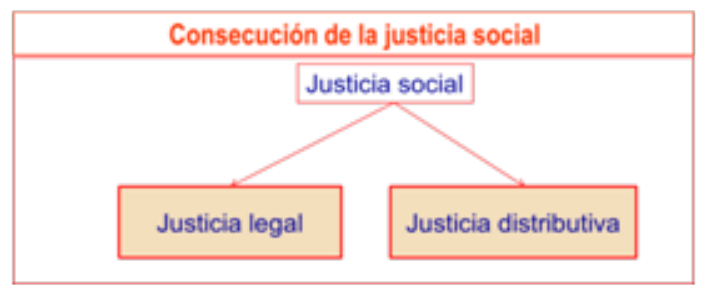

2. La formación de una sociedad con igualdad de oportunidades. A través de ac-

20 De acuerdo con Raúl Chanamé (2009: 81) la Constitución del Perú de 1920 incorpora el constitucionalismo social, se nutrió de elementos de la Constitución de Querétaro (1917) e incluso de la Constitución de Weimar (1919).

21 Los derechos de primera generación corresponden a las libertades individuales (vida, libertad, libre expresión, a no ser esclavizado ni torturado), mientras que el derecho a gozar de un ambiente saludable, a la paz, al desarrollo y al patrimonio común de la humanidad son los derechos de tercera generación o derechos de solidaridad.

22 Victor García, op. cit., pp.164-165 
ciones de fomento e impulso estatal se tiende a que la libertad y los demás derechos reconocidos a las personas se hagan efectivos y se aspire a remover todos los obstáculos que dificultan su plenitud.

\section{Diagrama N.o 18:}

\section{Igualdad de oportunidades vs. libertad y} demás derechos reconocidos

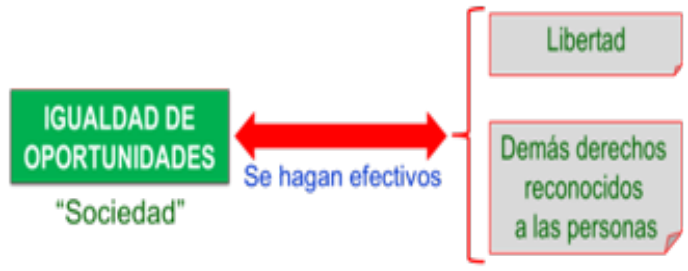

3. Reconocimiento y protección de los derechos económico-sociales denominados de segunda generación. Con especial énfasis en la consignación constitucional del derecho al trabajo, libertad de asociación, derechos grupales, salud, seguridad social, educación, etc.

Diagrama N.o 19:

Derechos económicos-sociales

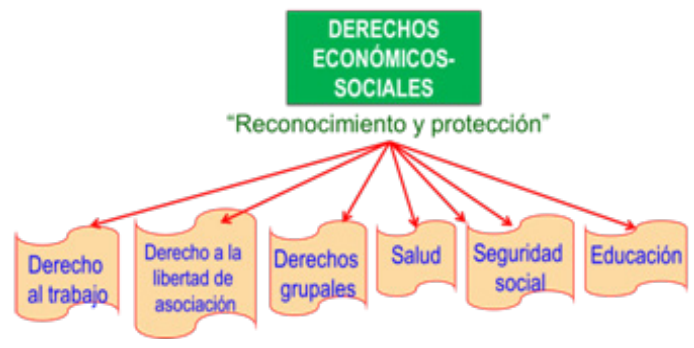

4. Incorporación sistémica de normas constitucionales referidas a la relación y papel del Estado con el fenómeno económico y los derechos y libertades conexas. Para tal efecto, se establece un marco jurídico regulatorio de la vida económica de una comunidad.
Diagrama N.o 20:

Constitución Económica como marco fundamental para contribuir al desempeño económico

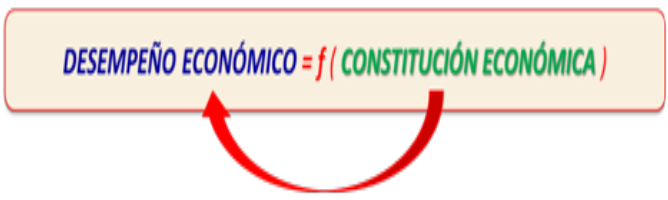

De ese modo una Constitución Económica establece el marco institucional que fundamenta el desempeño económico de un país.

\section{FUNDAMENTACIÓN TEÓRICA DE LA CONSTITUCIÓN ECONÓMICA}

\subsection{Relación entre el derecho y la economía}

Ronald H. Coase $\mathrm{e}^{23}$ considera muy importante el sistema legal en el mundo moderno; descubrió y aclaró la importancia de los costos de transacción y de los derechos de propiedad para el funcionamiento de la economía; específicamente, sostiene que los derechos económicos son fundamentales para la estructura institucional y el funcionamiento de la economía. Este planteamiento abrió el campo del Derecho y la Economía; ha permitido el surgimiento de una nueva rama de estudio: el Derecho Económico; el mismo que se concibe como las reglas de juego que rigen el sistema económico.

El Derecho, como conjunto de normas imperativas, prohibitivas, punitivas que el Estado impone a la sociedad, con la finalidad de garantizar el orden, la paz y la tranquilidad social, constituye un fenómeno histórico en constante evolución. En ese sentido, el Estado democrático y social, en su tarea reguladora, recurre al Derecho para:

23 Ronald H. Coase (Gran Bretaña) obtuvo el Premio Nobel de Economía en el año 1991 "Por su contribución al esclarecimiento de la importancia de los costos de transacciones y de los derechos económicos para la estructura institucional y el funcionamiento de la economía”. 
a) Reglamentar las relaciones económicas entre los diversos agentes económicos (familias, empresas, gobierno y agentes externos).

b) Definir la organización de la sociedad y del propio Estado.

c) Establecer reglas de juego claras en lo político, económico y social.

d) Crear los mecanismos que resuelvan los conflictos de intereses dentro de un contexto de paz social.

\subsection{Constitución Política}

Carl Schmitt (1982: 33-7) sostiene que Constitución en sentido absoluto puede significar una regulación legal fundamental, es decir, un sistema de normas supremas y últimas (Constitución=norma de normas) (...). La relativización del concepto de Constitución consiste en que en lugar de fijarse el concepto unitario de Constitución como un todo, se fija sólo el de ley constitucional concreta, pero el concepto de ley constitucional se fija según características externas y accesorias, llamadas formales. Constitución, en sentido relativo, significa, pues, la ley constitucional en particular.

$\mathrm{Al}$ respecto, Víctor García ${ }^{24}$ cita a Reynaldo Vanossi quien señala que: "La Constitución es el enunciado institucional de las grandes reglas de juego político y social que una comunidad adopta, para un cierto tiempo de su devenir histórico, por medio de un determinado repar- to de competencias y con proyección u orientación hacia ciertos fines en los que la sociedad visualiza su porvenir". La Constitución tiene las partes siguientes:

Diagrama N.o 21: Partes de una Constitución Política

A. Parte dogmática. Contiene una declaración de derechos fundamentales. No es objeto de exploración por la ciencia, se acepta como tal.

B. Parte orgánica. Comprende la organización de los organos del Estado. Regula la estructura del Estado. Trata de normar el poder política ${ }^{25}$

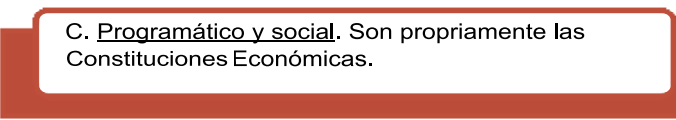

3.3 CONSTITUCIÓN ECONÓMICA

Sobre la regulación de aspectos económicos en una Constitución existen dos posiciones:

- Establecer un régimen económico (resulta fundamental determinar la intervención del Estado en la economía).

- Eliminar toda referencia relacionada al régimen económico (ya que con la enumeración de los derechos fundamentales sería suficiente para asegurar que el Estado no intervenga donde no debe hacer$\left.10^{26}\right)$.

Para Omar Cairo (1998: 166) los precedentes del constitucionalismo económico se encuentran en la Carta Magna de 1215, en la que se estableció una limitación a la potestad tributaria del Monarca. Se dispuso que el rey

24 Victor García, po. cit., p410

25 Todo poder regulado por la Constitución es político. El poder político es uno solo; consiste en la combinación variable de autoridad legítima y de poder público, que permiten a determinadas personas decidir por la sociedad en su conjunto y de ordenar a ésta con el objeto de ejecutar las decisiones adoptadas. El poder político en el plano nacional está conformado por los denominados Poderes del Estado: Ejecutivo, Legislativo y Judicial; y por los Órganos Constitucionales Autónomos (OCAs) órganos que comparten atribuciones con los poderes del Estado, aunque su esfera de poder es más especializada y concentrada. Los OCAs son: Contraloría General de la República, Banco Central de Reserva, Superintendencia de Banca, Seguros y Administradoras Privadas de Fondos de Pensiones, Consejo Nacional de la Magistratura, Ministerio Público, Defensoría del Pueblo, Jurado Nacional de Elecciones, Oficina Nacional de Procesos Electorales, Registro Nacional de Identificación y Estado Civil, Tribunal Constitucional.

26 Otros autores como Milton Friedman -Premio Nóbel de Economía en 1976- considera necesario enumerar los principios generales que funcionen como marco institucional de la acción estatal. 
no exigiera tributo a sus súbditos sin el consentimiento de los mismos. Se trata de un tema político y a la vez económico, que originó el actual principio de legalidad en materia tributaria.

Según Juan Vicente Sola (2004: 19) la primera visión de una teoría económica de la Constitución fue creada por Charles Beard en una obra muy difundida particularmente en las décadas de los años veinte y treinta en la que sostenía que el objetivo de la Constitución era el de redistribuir la riqueza de los sectores más pobres de la sociedad hacia las clases más poderosas que eran a las que pertenecían los constituyentes de Filadelfia. Argumentaba también que la Constitución era un documento económico para sostener los privilegios de la clase alta, propietaria de las tierras y esclavista, frente a las acciones de sectores empobrecidos.

Domingo García (1993: 51) afirma que el término Constitución Económica circula a partir del siglo XX, específica y concretamente en la década de 1920 en Alemania con la República de Weimar y su uso se generaliza en 1925, con Carl Schmitt quien lo incorpora a la literatura jurídica, con la aparición de su obra $\mathrm{La}$ Defensa de la Constitución en 1931. Es así, que Schmitt menciona el término Constitución Económica mostrando su preocupación por la adopción de un régimen que posea una fundamentación económica.

Vicente Acosta (2003: 328) argumenta que el origen del término Constitución Económica tiene que ver con el surgimiento del Estado Social de Derecho o Constitucionalismo Social, que en buena cuenta se caracterizó por adicionar a los derechos fundamentales los llamados derechos sociales, que limitaban los derechos individuales (por ejemplo la propiedad) en función de las necesidades nacidas de la convivencia social.

Para Dalla Via (1999: 49), el Derecho Constitucional Económico es el conjunto de disposiciones de rango constitucional de ordenación de la vida económica.

Kresalja y Ochoa (2009: 142) citan a Albertí quien sostiene que lo determinante no es un modelo económico, sino las normas jurídicas de desarrollo constitucional que desde la Constitución se proyectan sobre las relaciones económicas, las que constituyen el Derecho Constitucional Económico. Argumenta que no hay una Constitución Económica, sino un Derecho Constitucional Económico.

Para Christian Guzmán (2009: 29) el problema surge cuando las normas jurídicas que rigen el sistema no son claras, son demasiado flexibles o son modificadas de manera continua por el poder estatal. El riesgo para el funcionamiento del mercado es demasiado alto, puesto que el mismo puede mostrar distorsiones de las cuales no adolecería ante normas adecuadas. Dichas normas deben estar consagradas en una Constitución, puesto que la misma, en tanto norma suprema y relativamente rígida, genera importantes garantías de que el gobierno de turno no intentará vulnerar el ordenamiento ni lo modificará cada vez que lo considere conveniente. Asimismo, deben ser normas claras establecidas en término de limitación al poder estatal.

El Tribunal Constitucional en el fundamento 4 del EXP. N.o 0008-2003-AI/TC ha precisado que si bien es posible aplicar a la Norma Fundamental los criterios interpretativos propiamente aplicables a las normas de rango legal (a saber, los métodos literal, sistemático, histórico y sociológico), no es menos cierto que la Constitución posee también un importante contenido político, dado que incorpora no sólo reglas imperativas de exigencia o eficacia inmediata o autoaplicativa, sino también un cúmulo de disposiciones que propugnan el "programa social" del Estado, en una de cuyas vertientes principales se sitúa el régimen económico constitucional. 
El mismo Tribunal Constitucional en el fundamento 6 sostiene que la interpretación social permite maximizar la eficiencia de los derechos sociales y culturales en los hechos concretos, de modo tal que las normas programáticas ${ }^{27}$, en cuya concreción reside la clave del bien común, no aparezcan como una mera declaración de buenas intenciones, sino como un compromiso con la sociedad dotado de metas claras y realistas.

Dicho de otro modo, una Constitución Económica es el conjunto de normas con rango constitucional en la cual se establece el marco institucional que fundamenta el régimen económico de un país para un determinado tiempo de su devenir histórico, la organización jurídica de las estructuras, las relaciones económicas así como el funcionamiento de las actividades económicas, las cuales se orientan a garantizar la gobernabilidad de un país ${ }^{28}$. La esencia de una Constitución Económica es que no puede ser modificada por el procedimiento legislativo ordinario.

\section{REGLAS DE JUEGO CLARAS Y DES- EMPEÑO ECONÓMICO}

Las reglas de juego claras son aquellas instituciones o restricciones necesarias que dan estabilidad al sistema económico y limitan el poder estatal del gobierno de turno.

$\mathrm{Al}$ respecto, Douglass North ${ }^{29}$ (2007: 81) sostiene que toda actividad organizada por los hombres entraña una estructura destinada a definir "la manera de jugar el juego", se trate de una actividad deportiva o del funcionamiento de una economía. Esa estructura está compuesta de instituciones: reglas formales (definidas por el mandato de la Ley), reglas informales (definidas por las normas o convenciones sociales) y las características para garantizar su cumplimiento (...). La estructura que crean los seres humanos para ordenar su medio ambiente político y económico es el determinante básico del desempeño económico.

Debido a esto, el Enfoque Institucional de la Economía incorpora la Teoría de las Instituciones a la Teoría Económica; comprende:

\section{Diagrama N.o 22:}

\section{Elementos del Enfoque Institucional de la} Economía

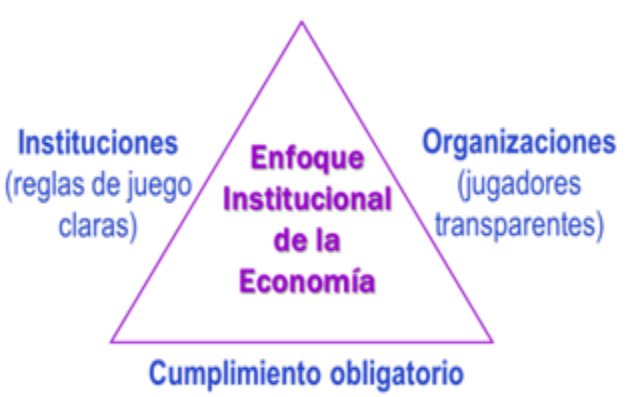

El institucionalismo nos enseña que la importancia del Estado radica en su rol como garante de los derechos de propiedad, del cumplimiento de los contratos, así como reducir los costos de transacción y atenuar los problemas de información. Con un Estado fuerte institucionalmente, se incrementa el intercambio y aumentan las ganancias de la actividad comercial.

José Ayala (2004: 354-5) sostiene que en la Teoría Neoclásica, el desempeño de la eco-

27 Son aquellas que establecen lineamientos o principios para ser cumplidos por los órganos del Estado, como programas de sus respectivas actividades, con el propósito de realizar los fines sociales del Estado.

28 El concepto de gobernabilidad se ha ido acuñando en el ámbito latinoamericano para indicar algo más amplio que governance (ejercicio del poder o la función de gobernar), pues no solo se refiere al ejercicio del gobierno sino, además, a todas las condiciones necesarias para que esta función se pueda desempeñar con eficacia, legitimidad y respaldo social. Se relaciona con la continuidad de las reglas de juego en el proceso del devenir histórico de un país.

29 Premio Nobel de Economía en 1993, en su obra Instituciones, cambio institucional y desempeño económico (1990), expone el marco analítico para explicar las formas en que las instituciones y los cambios institucionales afectan la economía. 
nomía es una función de los precios de los factores de la producción: Tierra $(\mathrm{T})$, Trabajo (W) y Capital (K), es decir:

Desempeño económico $=\mathrm{f}(\mathrm{T}, \mathrm{W}, \mathrm{K})$.

En cambio, para los Neoinstitucionalistas el desempeño económico es un resultado de los precios relativos de los factores de la producción, pero también de los diversos conjuntos institucionales Qn, es decir: Desempeño económico $=\mathrm{f}(\mathrm{T}, \mathrm{W}, \mathrm{K}, \mathrm{Q} 1 \ldots \ldots \mathrm{Qn})$.

La variable $Q n$, representa diferentes conjuntos institucionales cuya definición depende, en último término, del Estado, por ejemplo, garantizar los derechos de propiedad Q1, cumplimiento de contratos $\mathrm{Q} 2$, atenuar los problemas de información Q3, reducción de los costos de transacción Q4, etc.

Dani Rodrik (2011: 222-3) argumenta que un sistema de derechos de propiedad claramente definido, un aparato regulatorio que ponga freno a las peores formas de fraude, la conducta anticompetitivas y el riesgo moral; una sociedad moderadamente cohesiva que muestre rasgos de confianza y cooperación social; instituciones políticas y sociales que mitiguen el riesgo y manejen los conflictos sociales; un Estado de derecho y un gobierno limpio; todos estos son arreglos que los economistas normalmente dan por sentados, pero que están notablemente ausentes en los países pobres.

Economías que exhiben un pobre desempeño tienen una matriz institucional que no proporciona incentivos a las actividades capaces de mejorar la productividad.

Para North (2007: 82) el marco institucional consiste:
Diagrama N.o 23:

Marco institucional

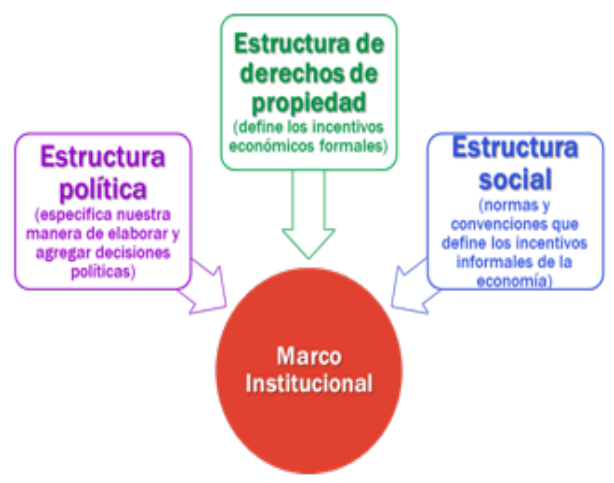

\section{CONSTITUCIÓN ECONÓMICA DEL PERÚ DE 1993}

5.1 Contexto de la Constitución Política de 1993

De acuerdo con Krugman ${ }^{30}$ la economía inevitablemente ocurre en un contexto político y uno no puede entender al mundo tal como era hace unos pocos años sin tomar en cuenta el hecho político fundamental de los años noventa: el colapso del socialismo, no solamente como una ideología de gobierno, sino como una idea con el poder para mover las mentes de los hombres. De manera extraña, ese colapso comenzó en China. Ciertamente le tomó al resto del mundo un tiempo largo darse cuenta de que 1,000 millones de personas habían abandonado silenciosamente el marxismo.

Es más, para Margaret Thatcher ${ }^{31}$, la Filosofía en el mundo durante los años setenta era: Nacionalización, Centralización, Control, Regulación $^{32}$.

30 Krugman, op. cit.,pp22-26.

31 Política británica que ejerció como primera ministra del Reino Unido desde 1979 a 1990. Thatcher fue elegida primera ministra el día de cumpleaños de Hayek.

32 Documental "Batalla por la Economía Mundial" (Barker 2002). 


\section{Diagrama N.o 24:}

Filosofía en el mundo durante los setenta

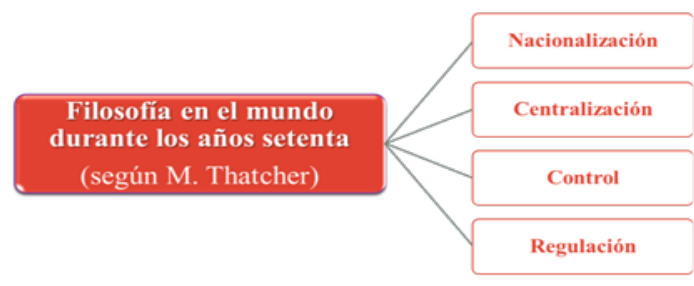

Estudiando en Oxford Margaret Thatcher leyó la obra de Hayek Caminos de servidumbre causando en ella una gran impresión. Años más tarde cuando llegó a ser la primera mujer líder del partido conservador arrojó el libro de Hayek en la mesa de reuniones y pronunció: ¡En esto es en lo que creemos!.

La asunción al poder de Thatcher marcó el punto de quiebre en la política mundial, ya que antes de asumir el gobierno, Gran Bretaña atravesaba por lo que se denominó el invierno del descontento caracterizado por las huelgas. En tal sentido, el gobierno de Thatcher, caracterizado por ser un gobierno conservador, reorientó la política de ese país.

Según Thatcher: "La libertad económica y las libertades individuales siempre van de la mano". Uno de sus inventos fue la privatización $^{33}$ (el 75\% de las minas de carbón eran deficitarias), puso casi todos los puestos de mando de la economía británica en venta: del Estado al mercado. En poco tiempo, las 2/3 partes de la industria estatal pasaron al sector privado $^{34}$.

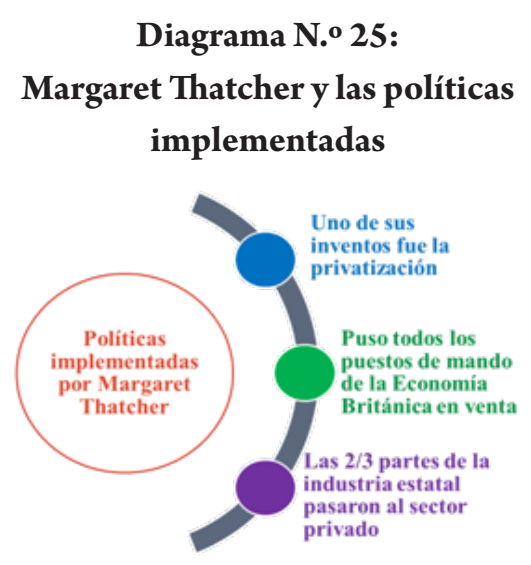

Los puestos de mando de la economía británica a finales de los setenta fueron privatizados.

\section{Diagrama N.o 26:}

Puestos de mando de la economía británica

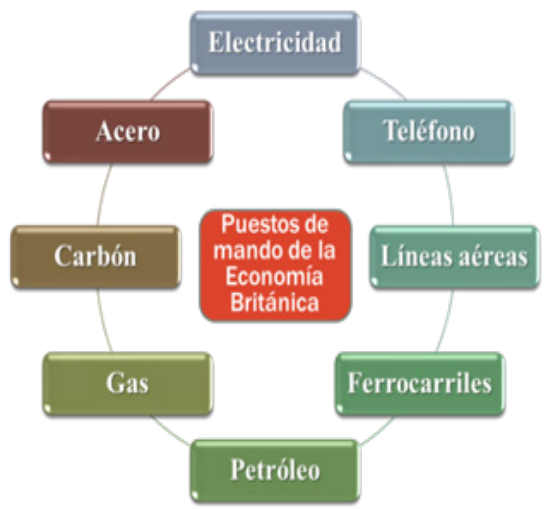

Paralelamente, Ronald Reagan (19112004) durante su gobierno estuvo contra la ortodoxia keynesiana y a favor de Hayek y Friedman. Su política (1982) recibió el nombre de Reaganomía ${ }^{35}$ y se componía de cuatro ingredientes básicos: moneda fuerte, liberalización, moderación impositiva, recorte del gasto público $^{36}$.

33 La privatización consiste en la transferencia o venta al sector privado de la propiedad del Estado (empresas públicas). En general, la privatización se puede realizar de dos formas: transfiriendo la propiedad o transfiriendo la administración de la actividad. La teoría de la privatización se basa en que estas empresas funcionan de manera más eficiente y ofrecen mejor servicio a los clientes cuando las poseen empresarios privados en vez del gobierno.

34 Documental "Batalla por la Economía Mundial" (Barker 2002).

35 Es una contracción de las palabras Reagan y economía que se usa para describir la política económica del gobierno de Estados Unidos presidido por Ronald Reagan durante los años ochenta.

36 Documental “Batalla por la Economía Mundial” (Barker 2002). 
Diagrama N.o 27:

Ronald Reagan: políticas implementadas en 1982

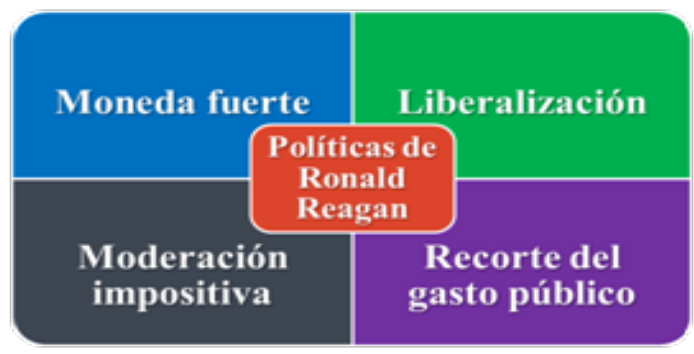

Para Krugman todo el mundo se daba cuenta de que algo había cambiado y ese "algo" era el colapso de la Unión Soviética. Es así que los efectos del derrumbe se sintieron alrededor del mundo. En primer lugar, varios cientos de millones de personas que habían vivido bajo regímenes marxistas se hicieron de repente ciudadanos de Estados dispuestos a darles a los mercados una oportunidad. Otro efecto fue que algunos gobiernos que dependían de su generosidad ahora se quedaban solos. Cuando Cuba parecía una nación heroica, al enfrentarse sola y con el puño cerrado a EE.UU, era un símbolo atractivo para los revolucionarios en toda América Latina.

Otro efecto, según Krugman, fue la desaparición de muchos de los movimientos radicales; de hecho sólo podían funcionar porque Moscú suministraba armas, campos de entrenamiento y dinero. Más que cualquier cosa, el fracaso del Unión Soviética destruyó el sueño socialista.

\section{Diagrama N.o 28:}

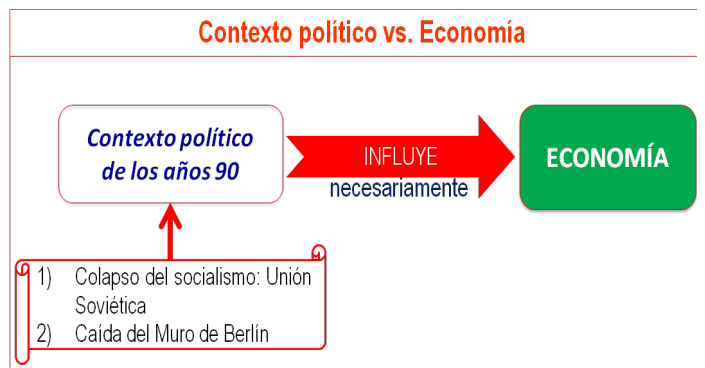

Los líderes nacionalistas invocaban los ideales socialistas mientras bloqueaban la inversión extranjera o repudiaban la deuda externa; los sindicatos usaban la retórica del socialismo para exigir mayores salarios, e incluso los hombres de negocios acudían a principios vagamente socialistas para exigir aranceles o subsidios.

En general, el contexto mundial a finales de los ochenta e inicio de los noventa estuvo marcado por la caída del Muro de Berlín (1989) ${ }^{37}$ y la desintegración de la URSS $(1991)^{38}$, consecuentemente el fin de la guerra fría ${ }^{39}$, ya que antes de estos hechos se presentó en el mundo una situación de disputa internacional creada entre las 2 mayores superpotencias del mundo (EE.UU-URSS) por la hegemonía del mundo, donde los otros países debían ceder a uno de los polos de influencia ${ }^{40}$.

37 El Muro de Berlín fue parte de las fronteras interalemanas (agosto 1961 - noviembre 1989) y separó a la República Federal Alemana o capitalista (Alemania Occidental) de la República Democrática Alemana o socialista (Alemania Oriental o Alemania del Este). Se extendía a lo largo de $45 \mathrm{~km}$ que dividían la ciudad de Berlín en dos y $115 \mathrm{~km}$ que separaban a la parte occidental de la oriental. Fue uno de los símbolos más conocidos de la Guerra Fría y la separación de Alemania.

38 La desintegración de la Unión de Repúblicas Socialistas Soviéticas (URSS) se inició con las reformas de Mijail Gorbachov en la llamada "Perestroika" (reformas estructurales sobre la organización política y económica) y posteriormente, en la "Glasnot" (política de transparencia cultural de los países socialistas hacia occidente).

El 21/12/1991, los gobiernos de 11 repúblicas acordaron crear la Comunidad de Estados Independientes (CEI), en reemplazo de la Unión de Repúblicas Socialistas Soviéticas; asumiendo Rusia el liderazgo. Ante esta coyuntura Gorbachov renunció y en su reemplazo asumió el gobierno Boris Yeltsin. El 21/12/1993 Yeltsin disolvió el parlamento y convocó a referéndum para aprobar una nueva Constitución.

39 La Guerra Fría es el estado de conflicto o desconfianza, próximo a operaciones de guerra abierta que se dio entre EE.UU y la ex Unión Soviética después de la Segunda Guerra Mundial.

40 A la situación de disputa internacional entre estas dos grandes potencias se le conoció como bipolaridad. Para mantener el equilibrio estratégico y alcanzar la primacía en el mundo, ambas potencias desarrollaron una carrera armamentista sin precedentes y la formación de bloque político-militares con los Estados de su área de influencia. 
En palabras de Stiglitz (2003: 37) "El final de la Guerra Fría entronizó a EE.UU como superpotencia hegemónica, subrayando la victoria de la economía de mercado sobre el socialismo. El mundo había dejado de estar dividido por razones ideológicas".

Con la caída de los regímenes socialistas a fines de los ochentas y principios de los noventas, revivieron las viejas ideas del liberalismo; resurgió la idea de que un despliegue (de ideas) de fuerzas individuales, sin el freno del Estado, conducirá al bienestar colectivo o bien común.

Joseph Stiglitz (2008: 113) sostiene que la austeridad fiscal, la privatización y la liberalización de los mercados fueron los tres pilares aconsejados por el Consenso de Washington durante los años ochenta y noventa. Las políticas del consenso fueron diseñadas para responder a problemas muy reales de América Latina, y tenía mucho sentido.

\section{Diagrama N. 0 29:}

\section{Pilares del Consenso de Washington}

(1989)

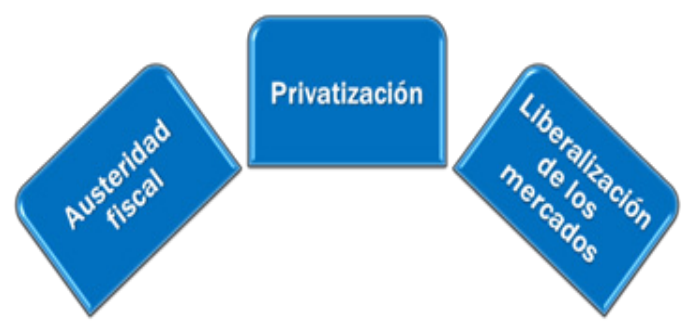

Nuestro país durante el final de la década del ochenta estuvo marcado por la crisis inflacionaria. De acuerdo con Carlos Boloña (1995: 65), de 1983 a 1990, la inflación pro- medio anual fue de 1,400\% anual y de 1991 a 1992 de $98 \%$ anual. La inflación subió de 61\% en 1980 a $158 \%$ en 1985. Luego experimentó una disminución a 63\% en 1986 debido a la aplicación de controles de precios; para más tarde manifestarse a través de una escalada que llegó a 115\% en 1987, 1,700\% en 1988, 2,800\% en 1989 y 7,650\% en 1990 . Tras la aplicación del programa económico, la inflación se redujo a $139 \%$ en 1991 y $57 \%$ en $19922^{41}$.

Debido a esta crisis inflacionaria, el control de la inflación se volvió prioritario. Ello se debió, entre otras cosas, a la agenda establecida para Latinoamérica en el Consenso de Washington ${ }^{42}$.

Carol Wiese ${ }^{43}$ sostiene que la creciente polarización entre derecha e izquierda, entre ortodoxia y heterodoxia, indicaban que los grupos locales no sabían todavía cómo enfrentar los problemas del país. De ahí la elección de un candidato independiente poco convencional, el cual conduciría la economía política peruana en una nueva dramática dirección durante toda la década de 1990.

En palabras de Stiglitz (2003: 13-50): "Hoy en día existe una pugna ideológica entre quienes abogan por reducir al mínimo la intervención del Estado en la economía y quienes sostienen que el gobierno debe asumir un papel importante, si bien limitado, no sólo para corregir las carencias y limitaciones del mercado, sino también para tender hacia un grado más alto de justicia social.

Tanto la izquierda como la derecha han perdido la brújula. Los fundamentos intelectuales de la economía del laissez faire se han derrumbado estrepitosamente. Hoy el reto

41 El proceso hiperinflacionario se debió al desmesurado incremento de la emisión monetaria en 116\% en 1987, 440\% en 1988 y $2400 \%$ en 1989 . La producción cayó en $24 \%$ entre 1988 y 1990.

42 Para Joseph Stiglitz (2008: 113) la austeridad fiscal, la privatización y la liberalización de los mercados fueron los tres pilares aconsejados por el Consenso de Washington durante los años ‘ 80 y ‘ 90 . Las políticas del consenso fueron diseñadas para responder a problemas muy reales de América Latina, y tenía mucho sentido; (...) los gobiernos habían perdido todo control presupuestario y las políticas monetarias condujeron a inflaciones rampantes (Stiglitz 2008: 55).

43 Obra citada, página 229 
consiste en lograr un equilibrio correcto: entre Estado y mercado.

Diagrama N.o 30:

Reto: lograr equilibrio correcto entre el Estado y el mercado

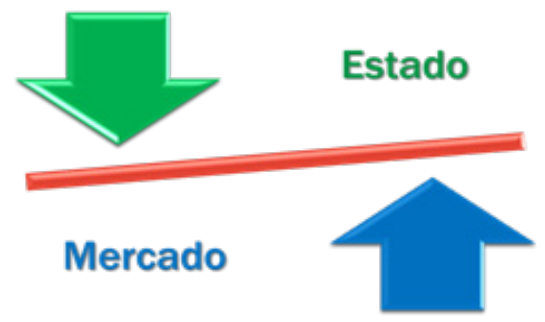

La regulación ejercida por el gobierno puede y suele desempeñar un papel importante con miras a lograr un mejor funcionamiento de los mercados".

5.2 Reglas de juego en materia económica en la Constitución de 1993

En noviembre de 1992, se eligieron los representantes para el Congreso Constituyente Democrático (CCD), quienes elaboraron la Constitución que se aprobó mediante referéndum en 1993. Específicamente, el Título III se refiere al Régimen Económico y consta de seis capítulos $^{44}$. En tal sentido, las principales reglas de juego en materia económica establecidas en la Constitución de 1993 son las siguientes ${ }^{45}$ :

\Iniciativa privada libre dentro de una economía social de mercado. La iniciativa privada es libre. Se ejerce en una economía social de mercado. Bajo este régimen, el Estado orienta el desarrollo del país, y actúa principalmente en las áreas de promoción de empleo, salud, educación, seguridad, servicios públicos e infraestructura (artículo 58 $)^{46}$.

Nuestra economía de mercado debe ser social, en el sentido de que ciertos excesos del mercado deben ser regulados para garantizar el bien común ${ }^{47}$.

\section{Diagrama N.o 31 :}

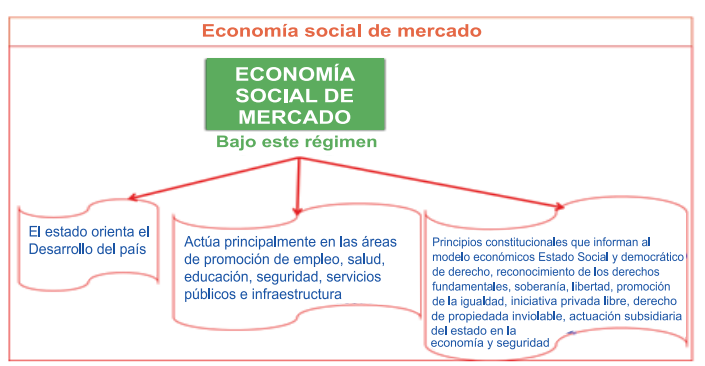

La economía social de mercado es representativa de los valores constitucionales de la libertad y la justicia, y, por ende, es compatible con los fundamentos axiológicos y teleológicos

44 Capítulo I: principios generales; II: ambiente y recursos naturales; III: propiedad; IV: régimen tributario y presupuestal; V: moneda y banca; VI: régimen agrario y comunidades campesinas y nativas

45 El Tribunal Constitucional a través del EXP. N. ${ }^{\circ}$ 0008-2003-AI/TC - F.J. 9-25 ha dejado establecido que los principios constitucionales que informan al modelo económico son: 1) Estado peruano como Estado Social y Democrático de Derecho (Comunidad política fundamentada en las exigencias establecidas para el Estado de Derecho -cuyos principios y derechos son la libertad, seguridad, propiedad privada e igualdad ante la ley- fundamentada en la convivencia dentro de un orden económico y social con vocación de plasmar la justicia social y por ende, generar una sociedad con igualdad de oportunidades para todos, así como también, apuntalada con los principios-valores contenidos en la ideología democrática); 2) Dignidad de la persona humana; 3) Igualdad; 4) Economía social de mercado (opuesto tanto a la economía de planificación y dirección central como a la economía del laissez faire, en donde el Estado no puede ni debe inmiscuirse en el proceso económico), 5) Libre iniciativa privada (derecho a emprender y desarrollar, con autonomía plena, la actividad económica de su preferencia); 5) Actuación subsidiaria del Estado en la economía.

46 En la Constitución de 1979 la iniciativa privada es libre, pero es estimulada y reglamentada por el Estado, de modo que sea coherente con el interés social (artículo 115).

47 La Constitución de 1979 establecía que el Estado estimula y reglamenta el ejercicio de la iniciativa privada libre para armonizarlo con el interés social; en cambio en la Constitución de 1993 se da al Estado el carácter de orientador del desarrollo del país y le asigna ciertas áreas de actuación que tienen que ver con asuntos sociales esenciales: promoción de empleo, salud, educación, seguridad, servicios públicos e infraestructura. Esto quiere decir que en la actual Constitución el Estado no interviene en la libre iniciativa. 
que inspiran a un Estado Social y Democrático de derecho. En esta imperan los principios de libertad y promoción de la igualdad material dentro de un orden democrático garantizado por el Estado (...). Es decir, tanto como se opone a la economía de planificación y dirección central, la economía social de mercado se opone también a la economía del laissez faire, en donde el Estado no puede ni debe inmiscuirse en el proceso económico (EXP. N. ${ }^{\circ}$ 0008-2003-AI/TC) ${ }^{48}$.

De acuerdo con el Tribunal Constitucional, el Estado peruano definido por la Constitución de 1993, presenta las características básicas de Estado social y democrático de derecho. Así se concluye de un análisis conjunto de los artículos $3^{\circ}$ y $43^{\circ}$ de la Ley Fundamental. Asimismo, se sustenta en los principios esenciales de libertad, seguridad, propiedad privada, soberanía, separación de las funciones supremas del Estado y reconocimiento de los derechos fundamentales. Principios que se derivan la igualdad ante la ley y el necesario reconocimiento de que el desarrollo del país se realiza en el marco de una economía social de mercado (EXP. N.o 0008-2003-AI/TC F.J. 10$12)^{49}$.
Otro principio que informa a la totalidad del modelo económico es el de la libre iniciativa privada, prescrito en el artículo $58^{\circ}$ de la Constitución y que se encuentra directamente conectado con lo establecido en el inciso 17), artículo $2^{\circ}$ del mismo texto, el cual establece el derecho fundamental de toda persona a participar, ya sea en forma individual o asociada, en la vida económica de la Nación. De ello se colige que toda persona natural o jurídica tiene derecho a emprender y desarrollar, con autonomía plena, la actividad económica de su preferencia, afectando o destinando bienes de cualquier tipo a la producción y al intercambio económico con la finalidad de obtener un beneficio o ganancia material (EXP. N. ${ }^{\circ} 0008$ 2003-AI/TC) ${ }^{50}$.

Complementario a lo expresado anteriormente, el segundo párrafo del artículo $63^{\circ}$ establece que la producción de bienes y servicios es libre ${ }^{51}$.

Carlos Torres y Torres Lara (1994: 91) sostiene que fueron los alemanes quienes mejor desarrollaron en la práctica el concepto de la economía social de mercado con reglas que terminaron por reconocerse como uno de los mejores modelos social cristianos. Para Torres y Torres Lara, el sistema se basó en el estableci-

48 Como puede notarse el Tribunal Constitucional considera que la economía social de mercado, que se basa en el principio de promoción de la igualdad económica, se opone a la doctrina del liberalismo clásico y la economía planificada.

49 La seguridad jurídica y la igualdad ante la ley, a su vez, son condiciones necesarias para el funcionamiento del Estado social y democrático de derecho, y se configuran en un marco de condiciones vitales mínimas y de una posición estadual vigilante a través de los órganos autónomos y transparentes que promuevan el desarrollo del país en un marco de libre competencia e, igualmente, velen por el respeto de la dignidad de las personas.

El Estado social y democrático de derecho, como alternativa política frente al Estado liberal, asume los fundamentos de éste, pero además le imprime funciones de carácter social.

50 De acuerdo con Marcial Rubio (2008: 124) la libre iniciativa privada tiene como límite el no colisionar con los intereses generales, pero el poder público tiene como límite a la libre iniciativa privada en lo que se considera como "privativo" de la autodeterminación de los particulares. En la vida económica, la regla es la libre iniciativa privada y la excepción la intervención del poder público. Este se caracteriza como subsidiario de la libre iniciativa privada.

51 La Constitución de 1979 establecía que el Estado estimula y reglamenta el ejercicio de la iniciativa privada libre para armonizarlo con el interés social; en cambio en la Constitución de 1993 da al Estado el carácter de orientador del desarrollo del país y le asigna ciertas áreas de actuación que tienen que ver con asuntos sociales esenciales, promoción de empleo, salud, educación, seguridad, servicios públicos e infraestructura. 
miento de mecanismos de orientación indirecta de la economía. Estos instrumentos fueron tres: 1) impuestos, 2) aranceles y 3) control monetario.

\section{Diagrama N.o 32:}

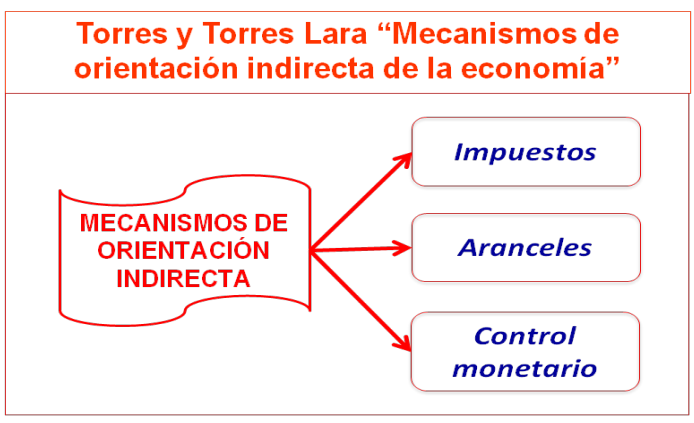

Libertad de empresa, comercio e industria $^{52}$. El primer párrafo del artículo 59० dispone que: "El Estado estimula la creación de riqueza y garantiza la libertad de trabajo ${ }^{53}$ y la libertad de empresa ${ }^{54}$, comercio $^{55}$ e industria $^{56}$. El ejercicio de estas libertades no debe ser lesivos a la moral, ni a la salud, ni a la seguridad pública..." La creación de riqueza es una de las fuentes de progreso de los pueblos, por eso el Estado debe estimularla.

La libertad de trabajo y las de empresa, comercio e industria son consistentes con la iniciativa privada libre tipificadas en el artículo $58^{\circ}$.

Igual tratamiento legal a la actividad empresarial, pública o no pública. No hay privilegios para la actividad empresarial privada ni pública. Pueden coexistir varios tipos de empresa simultáneamente: privadas, públicas, nacionales, extranjeras, mixtas, autogestionarias, cooperativas, etc.

52 Las libertades patrimoniales que garantizan el régimen económico actual son las siguientes: el derecho a la propiedad, el derecho a la libre contratación, la libertad de trabajo, la libertad de empresa, la libertad de comercio, la libertad de industria

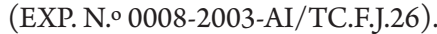

53 El inciso 15) del artículo $2^{\circ}$ dispone que la libertad de trabajo consiste en la atribución o facultad para elegir a voluntad la actividad ocupacional o profesional que cada persona desee desempeñar. Para tal efecto, dicha prerrogativa deberá ser ejercida con sujeción a la ley.

Para el Tribunal Constitucional la libertad de trabajo se formula como el atributo para elegir a voluntad la actividad ocupacional o profesional que cada persona desee o prefiera desempeñar, disfrutando de su rendimiento económico y satisfacción espiritual; así como de cambiarla o de cesar de ella. Para tal efecto, dicha facultad autodeterminativa deberá ser ejercida con sujeción a la ley. Por ello es que existen limitaciones vinculadas con el orden público, la seguridad nacional, la salud y el

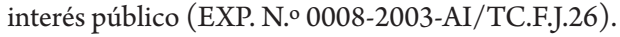

54 El Tribunal Constitucional en el EXP. N. 3330-2004-AA/TC.F.J.11-13 ha establecido que la libertad de empresa se manifiesta como el derecho de las personas a elegir libremente la actividad ocupacional o profesional que desee o prefiera desempeñar, disfrutando de su rendimiento económico y satisfacción espiritual. Asimismo, considera que el contenido de la libertad de empresa está determinado por cuatro libertades:

a) libertad de creación de empresa y de acceso al mercado (libertad para emprender actividades económicas en el sentido de libre fundación de empresas y concurrencia al mercado;

b) libertad de organización (contiene la libre elección del objeto, nombre, domicilio, tipo de empresa o sociedad mercantil, facultades a los administradores, políticas de precios, créditos y seguros, contratación de personal y política publicitaria, entre otros);

c) libertad de competencia;

d) libertad para cesar las actividades (libertad para disponer el cierre o cese de actividades de la misma cuando lo considere más oportuno).

55 La libertad de comercio se refiere a la facultad de elegir la organización y llevar a cabo una actividad ligada al intercambio de mercaderías o servicios, para satisfacer la demanda de los consumidores o usuarios. Debe ejercerse con sujeción a la ley. La libertad presupone el atributo de poder participar en el tráfico de bienes lícitos, así como dedicarse a la prestación de servicios al público no sujetos a dependencia o que impliquen el ejercicio de una profesión liberal (EXP. N. ${ }^{0} 0008-2003-\mathrm{AI} /$ TC.F.J.26)

56 La libertad de industria se refiere a la facultad de elegir y obrar, según propia determinación, en el ámbito de la actividad económica cuyo objeto es la realización de un conjunto de operaciones para la obtención y/o transformación de uno o

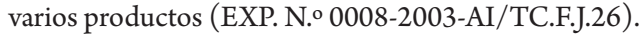

57 El pluralismo económico implica que pueden coexistir varios tipos de empresa simultáneamente: privadas, públicas, nacionales, extranjeras, mixtas, autogestionarias, cooperativas, etc. Cada una de ellas puede adoptar formas particulares de organizarse. 
El Estado reconoce el pluralismo económico $^{57}$. La economía nacional se sustenta en la coexistencia de diversas formas de propiedad y de empresa (... ). La actividad empresarial, pública o no pública, recibe el mismo tratamiento legal (artículo 60\%).

> Libre acceso a prestaciones de salud y pensiones. El Estado garantiza el libre acceso a prestaciones de salud y pensiones, a través de entidades públicas, privadas o mixtas. Supervisa asimismo su eficaz funcionamiento. La ley establece la entidad del Gobierno Nacional que administra los regímenes de pensiones a cargo del Estado (artículo 11 ${ }^{\circ}$ ). Las modificaciones que se introduzcan en los regímenes pensionarios actuales, así como los nuevos regímenes pensionarios que se establezcan en el futuro, deberán regirse por los criterios de sostenibilidad financiera y no nivelación.

Igualmente, la actual Constitución establece que los fondos y las reservas de la seguridad social son intangibles. Los recursos se aplican en la forma y bajo la responsabilidad que señala la ley (artículo $12^{\circ}$ ).

En consecuencia, nuestro ordenamiento jurídico constitucional ha tomado en cuenta el derecho al libre acceso a la pensión, así como la garantía constitucional de la seguridad social que sustenta el derecho al libre acceso a la pensión.

> Actuación subsidiaria del Estado en la economía ${ }^{59}$. El segundo párrafo del artículo $60^{\circ}$ regula el principio de subsidiariedad del Estado: sólo autorizado por ley expresa, el Es- tado puede realizar subsidiariamente actividad empresarial, directa o indirecta, por razón de alto interés público o de manifiesta conveniencia nacional ${ }^{60}$.

Diagrama N.o 33:

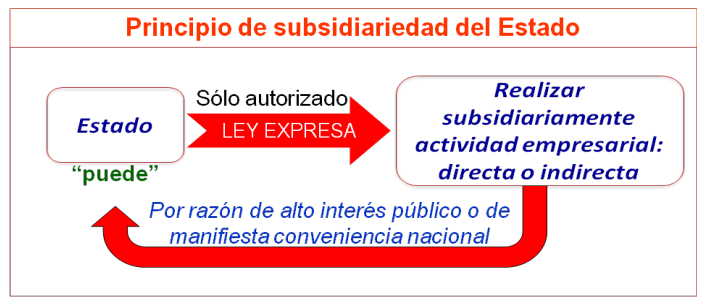

Con la finalidad de hacer efectivo dicho principio se debe cumplir con tres requisitos ${ }^{61}$ : 1) Autorización por ley, expresa, esto es, emitida por el Congreso de la República.

2) Por razón de interés público o de manifiesta conveniencia nacional.

3) Ante la ausencia de actividad privada en el sector del cual se trata.

$>$ Libre competencia. El primer párrafo del artículo $61^{\circ}$ dispone que "El Estado facilita y vigila la libre competencia. Combate toda práctica que la limite y el abuso de posiciones dominantes o monopólicas. Ninguna ley ni concertación puede autorizar ni establecer monopolios...". La libre competencia es incompatible con las posiciones dominantes o monopólicas. Según este artículo no hay concertación que pueda autorizar ni establecer monopolios por decisión gubernamental o particulares $^{62}$.

58 La Constitución de 1979 regulaba que la seguridad social está a cargo de una institución pública (artículo 14º).

59 En la Constitución de 1979 el Estado ejerce su actividad empresarial con el fin de promover la economía del país, prestar servicios públicos y alcanzar los objetivos de desarrollo (artículo 113º).

60 Si bien el principio de subsidiariedad, al que debe atenerse el accionar del Estado, y el respeto al contenido esencial de las libertades económicas, constituyen, básicamente, límites al poder estatal, la Constitución reserva al Estado, respecto al mercado, una función supervisora y correctiva o reguladora (EXP. N.o 0008-2003-AI/TC).

61 Para el Tribunal Constitucional el principio de subsidiariedad de la actuación del Estado plantea el reconocimiento de la existencia de una función supletoria del Estado ante la imperfección u omisiones de los agentes económicos, en aras del bien común. Considera que dentro del marco establecido por el principio de subsidiariedad y en el ejercicio de su actividad económica, el Estado, tal y conforme lo dispone el artículo 58 ${ }^{\circ}$, asume roles sociales en áreas tales como el de la promoción del empleo, salud, educación, seguridad, servicios públicos e infraestructura (EXP. N.o 0008-2003-AI/TC.F.J.23,24).

62 Sin embargo, el artículo $72^{\circ}$ tipifica una excepción constitucional a la economía de mercado y libre competencia: "La ley puede, sólo por razón de seguridad nacional, establecer temporalmente restricciones y prohibiciones específicas para la adquisición, posesión, explotación y transferencia de determinados bienes". Es así que en 1992 se prohibió la transferencia y posesión de anfo que utilizaban los terroristas como insumo para fabricar coches bomba. 
La libre competencia es un principio sobre el cual se inspira una economía de mercado. Se basa en la libre concurrencia de la oferta y la demanda, precios libres y ganancias libres. De este modo, la competencia es el objetivo prioritario y la regulación el instrumento necesario para defender la competencia. En consecuencia, para que exista y funcione el mercado con corrección, es preciso que el Estado cree un sistema jurídico-institucional adecuado.

Libre tenencia y disposición de moneda extranjera. El Estado garantiza la libre tenencia y disposición de moneda extranjera (artículo 64) ${ }^{63}$. Esta norma es consistente con la libre iniciativa privada establecida en la propia Constitución, ya que incluye la libertad de comprar y vender moneda extranjera dentro del Perú.

Cabe señalar que, la moneda al ser un bien podría aplicársele el artículo $72^{\circ}$. Sin embargo, dicho artículo no permite la prohibición de libre tenencia y disposición de moneda extranjera, debido a que no es posible que dicha prohibición pueda afectar la seguridad nacional, cuya interpretación en el supuesto caso debe ser restrictiva y no extensiva.

- Libertad de contratar. La libertad de contratar garantiza que las partes pueden pactar válidamente según las normas vigentes al tiempo del contrato. Los términos contractuales no pueden ser modificados por leyes u otras disposiciones de cualquier clase. Los conflictos derivados de la relación contractual sólo se solucionan en la vía arbitral o en la judicial, según los mecanismos de protección previstos en el contrato o contemplados en la ley (artículo $\left.62^{\circ}\right)^{64}$. Esto implica que cualquiera puede contratar con fines lícitos, siempre que no se contravengan leyes de orden público ${ }^{65}$.

Diagrama N.o 34:

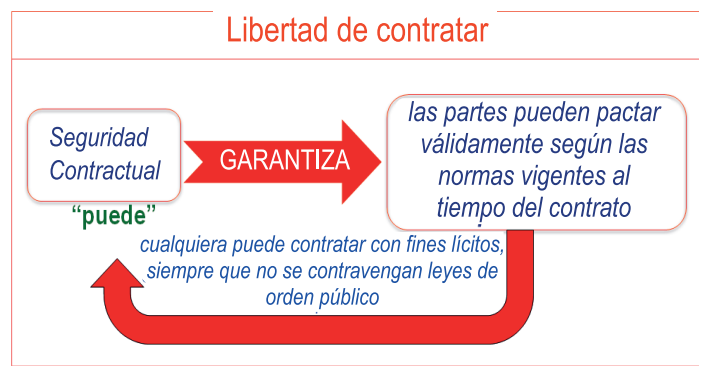

El derecho a la libre contratación establecido en el inciso 14) del artículo $2^{\circ}$, se concibe como el acuerdo o convención o voluntades entre dos o más personas naturales y/o jurídicas para crear, regular, modificar o extinguir una relación jurídica de carácter patrimonial. Dicho vínculo -fruto de la concertación de voluntades- debe versar sobre bienes o intereses que poseen apreciación económica, tener fines lícitos y no contravenir las leyes de orden público (EXP. N.o 0008-2003-AI/TC.F.J. 26).

$>$ Libre comercio exterior. El segundo párrafo del artículo $63^{\circ}$ establece el comercio exterior es libre. También dispone que si otro país o países adoptan medidas proteccionistas o discriminatorias que perjudiquen el interés nacional, el Estado puede, en defensa de éste, adoptar medidas análogas.

En estricto, ningún país puede mantener una economía cerrada o autárquica, sin tener relaciones económicas con el resto del mundo, ya que un país cualquiera se encuentra relacionado con el resto del mundo a través de dos grandes vías: el comercio (de bienes y servicios) y las finanzas.

63 Este artículo carece de antecedente en la Constitución de 1979.

64 Este artículo carece de antecedente en la Constitución de 1979.

65 El segundo párrafo del artículo $62^{\circ}$ dispone que "Mediante contratos-ley el Estado puede establecer garantías y otorgar seguridades. No pueden ser modificados legislativamente. ...." Los contratos-ley son acuerdos del Estado con inversionistas privados, a los que se les otorgan determinadas seguridades, generalmente de política económica o de naturaleza tributaria. Constituyeron una forma de garantizar la continuidad de reglas de juego a los inversionistas ya que durante los ochenta nuestro país era bastante riesgoso, caracterizado por la inestabilidad económica y política. 
Con relación a las importaciones, se debe precisar que la regulación de las tarifas arancelarias corresponde al Presidente de la República (artículo $118^{\circ}$, inciso 20).

Igualdad jurídica de la inversión. La inversión nacional y la extranjera se sujetan a las mismas condiciones (artículo 63 ${ }^{\circ}{ }^{66}$. Para César Landa (2008: 63) es importante que la inversión extranjera se someta al principio de igualdad de trato de la inversión nacional, lo que no obsta para que, excepcionalmente, el Estado pueda otorgar a la inversión extranjera un trato especial, que no suponga discriminación, sino diferenciación, lo que es constitucional ${ }^{67}$. Así, cualquier diferenciación de trato preferencial de la inversión extranjera, debe basarse en objetivos económicos razonables, acordes con los principios y valores constitucionales, el trato especial debe ser racional, es decir, conforme con los motivos que dan lugar a aceptar la inversión extranjera, el trato especial debe ser proporcional, no desmedido ${ }^{68}$.

Sistema monetario. La ley determina el sistema monetario de la República. La emisión de billetes y monedas es facultad exclusiva del Estado. La ejerce por intermedio del Banco Central de Reserva del Perú (artículo 83). Un sistema monetario implica la existencia de:
Diagrama N.o 35:

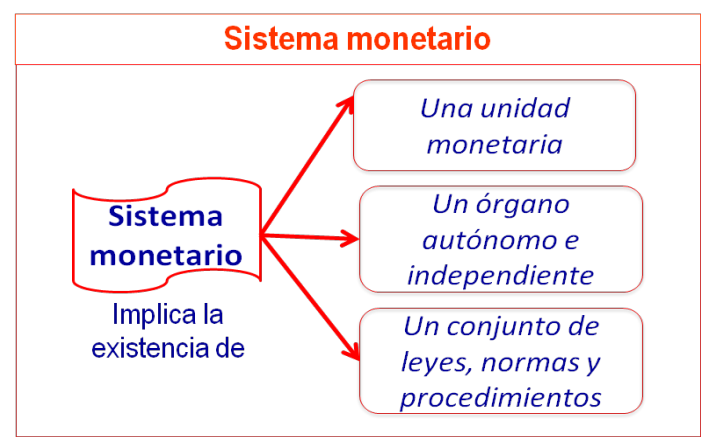

Finalidad de Banco Central de Reserva del Perú (BCRP): preservar la estabilidad monetaria. El segundo párrafo del artículo $84^{\circ}$ dispone expresamente que la finalidad del BCRP consiste en preservar la estabilidad monetaria ${ }^{69}$. En cambio, la Constitución de 1979 consideraba este aspecto como una de las funciones del BCRP. Preservar la estabilidad monetaria constituye un rol trascendente del BCRP, lo que se traduce en ausencia de grandes fluctuaciones en el valor de la moneda, esto es que nuestra moneda conserve su valor a lo largo del tiempo, que su poder adquisitivo no se diluya. Para ello es necesario, que mantenga la inflación bajo control, ya que no sólo influye negativamente en el nivel de producción, sino que genera un impuesto inflación (pérdida de capital que sufren los agentes económicos con su dinero como resultado de la inflación) que afecta significativamente a los sectores de bajos ingresos.

66 Para la Constitución de 1979 la inversión extranjera es complementaria a la nacional, siempre que contribuya al desarrollo, en concordancia con los planes económicos y la política de integración (artículo 1370).

67 La noción de igualdad debe ser percibida en dos planos convergentes. En el primero aparece como un principio rector de la organización y actuación del Estado Democrático de Derecho. En el segundo, se presenta como un derecho fundamental de la persona (...). La idea de igualdad se desprende de la dignidad y naturaleza de los seres humanos. El tratamiento desigual no será injustificado en tanto no se afecte dicha dignidad (EXP. N. ${ }^{\circ}$ 0261-2003-AA/TC). El principio de igualdad no garantiza que siempre y en todos los casos deba tratarse por igual a todos, sino que las diferenciaciones que el legislador eventualmente pueda introducir, obedezcan a razones objetivas y razonables (EXP. N. o 0010-2002-AI/TC).

68 El artículo $71^{\circ}$ constituye una excepción constitucional al principio de igualdad de tratamiento a la inversión nacional y extranjera: “... dentro de $50 \mathrm{~km}$ de las fronteras, los extranjeros no pueden adquirir ni poseer, por título alguno, minas, tierras, bosques, aguas, combustibles ni fuentes de energía, directa ni indirectamente, individualmente ni en sociedad, bajo pena de perder en beneficio del Estado, el derecho así adquirido. Se exceptúa el caso de necesidad pública expresamente declarada por Decreto Supremo aprobado por el Consejo de Ministros conforme a ley”.

69 El Banco Central es persona jurídica de derecho público. Tiene autonomía dentro del marco de su Ley Orgánica (artículo $84^{\circ}$ ). El BCRP es gobernado por un Directorio de siete miembros. El Ejecutivo designa a cuatro, entre ellos al Presidente. El Congreso ratifica a éste y elige a los tres restantes, con la mayoría absoluta del número legal de sus miembros (artículo $86^{\circ}$ ). 
Diagrama N.o 36:

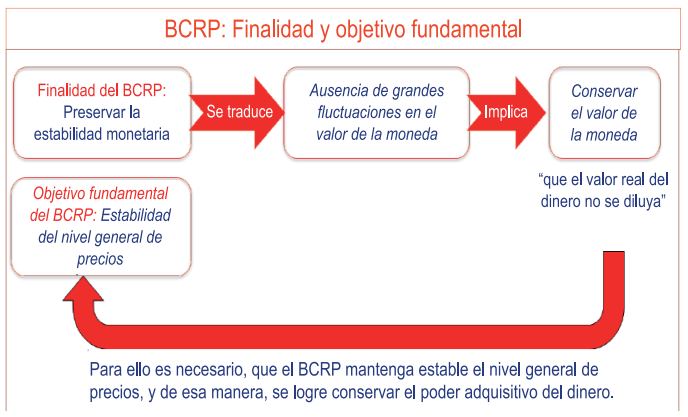

Con la finalidad de preservar la estabilidad monetaria, debe regular la cantidad de dinero en la economía y de acuerdo con la posición de los monetaristas, el incremento del circulante (billetes y monedas) que le corresponde emitir al BCRP debe ser compatible con el crecimiento de la actividad económica para no generar inflación. A esto último se conoce como disciplina monetaria ${ }^{70}$.

Prohibición del Banco Central de Reserva del Perú de financiar al erario. El último párrafo del artículo $84^{\circ}$ dispone expresamente que el BCRP está prohibido de conceder financiamiento al erario salvo la compra en el mercado secundario de valores emitidos por el Tesoro Público dentro del límite que señala su Ley Orgánica ${ }^{71}$.

La historia económica ha demostrado que cuando los bancos centrales no tienen independencia en muchas ocasiones se ven tentados a financiar al erario, rompiendo una regla básica en el ámbito monetario: la disciplina monetaria. En ese sentido, el Gobierno tiene una gran responsabilidad en materia monetaria: la emisión monetaria, la impresión de bille- tes o la acuñación de monedas, debe estar sujeta a reglas claras y no a la libre discrecionalidad de las autoridades monetarias.

Fomento del ahorro y supervisión de las empresas bancarias, seguros, administradoras privadas de fondos de pensiones. El Estado fomenta y garantiza el ahorro (...). La Superintendencia de Banca, Seguros y Administradoras Privadas de Fondos de Pensiones ${ }^{72}$ ejerce el control de las empresas bancarias, de seguros, de administración de fondos de pensiones, de las demás que reciben depósitos del público y de aquellas otras que, por realizar operaciones conexas o similares, determine la ley.

La ley establece la organización y la autonomía funcional de la Superintendencia de Banca, Seguros y Administradoras Privadas de Fondos de Pensiones.

El Poder Ejecutivo designa al Superintendente de Banca, Seguros y Administradoras Privadas de Fondos de Pensiones por el plazo correspondiente a su período constitucional. El Congreso lo ratifica (artículo 870).

Defensa de los consumidores y usuarios. El Estado defiende el interés de los consumidores y usuarios ${ }^{73}$. Garantiza el derecho a la información sobre los bienes y servicios que se encuentran a su disposición en el mercado. Una situación que justificaría la intervención directa en el ámbito de la protección al consumidor es la denominada información asimétrica.

70 Para Milton Friedman (1992: 29) "La inflación es siempre y en todas partes un fenómeno monetario en el sentido de que es y sólo puede ser producida por un aumento más rápido de la cantidad de dinero que la producción”.

71 La prohibición del BCRP de financiar al erario carece de antecedente en la Constitución de 1979.

72 La Ley de Reforma Constitucional N.o 28484 del 05/04/2005 modificó la denominación de Superintendencia de Banca y Seguros por la de Superintendencia de Banca, Seguros y Administradoras Privadas de Fondos de Pensiones.

73 Nuestra constitución distingue entre consumidores y usuarios con la finalidad de establecer que el usuario es un consumidor especial, puesto que hace uso de un servicio público. El servicio público es el conjunto de prestaciones que buscan asegurar la satisfacción de las necesidades colectivas de interés general sujeta a un régimen de derecho público y a una regulación específica. 
El Tribunal Constitucional a través del EXP. N. 0008-2003-AI/TC ha precisado lo siguiente:

El consumidor -o usuario- es el fin de toda actividad económica; es decir, es quien cierra el círculo económico satisfaciendo sus necesidades y acrecentando su bienestar a través de la utilización de una gama de productos y servicios. En puridad, se trata de una persona natural o jurídica que adquiere, utiliza o disfruta determinados productos (como consumidores) o servicios ${ }^{74}$ (como usuario) que previamente han sido ofrecidos al mercado.

Es indudable que la condición de consumidor o usuario se produce a través de la relación que éste entabla con un agente proveedor, independientemente de su carácter público o privado; sea en calidad de receptor o beneficiario de algún producto, sea en calidad de destinatario de alguna forma de servicio.

En consecuencia, la condición de consumidor o usuario no es asignado a cualquier individuo o ente, sino a aquel vinculado a los agentes proveedores dentro del contexto de las relaciones generadas por el mercado, las cuales tienen como correlato la actuación del Estado para garantizar su correcto desenvolvimiento.

El proveedor sería aquella persona natural o jurídica que, habitual o periódicamente, ofrece, distribuye, vende, arrienda o concede el uso o disfrute de bienes, productos y servicios.

Derecho de propiedad inviolable. El derecho de propiedad es inviolable. El Estado lo garantiza. Se ejerce en armonía con el bien común dentro de los límites de la ley. A nadie puede privarse de su propiedad sino, exclusivamente, por causa de seguridad nacional o necesidad pública, declarada por ley, y previo pago en efectivo de indemnización justipreciada que incluya compensación por el eventual perjuicio. Hay acción ante el Poder Judicial para contestar el valor de la propiedad que el Estado haya señalado en el procedimiento expropiatorio $\left(\text { artículo } 70^{\circ}\right)^{75}$.

El derecho de propiedad establecido en los incisos 8) y 16) del artículo $2^{\circ}$, es concebido como el poder jurídico que permite a una persona usar, disfrutar, disponer y reivindicar (reclamar) un bien. Así una persona propietaria podrá servirse directamente de su bien, percibir sus frutos y productos, y darle destino o condición conveniente a sus intereses, siempre que ejerza tales actividades en armonía con el bien común y dentro de los límites establecidos por la ley; e incluso podrá recuperarlo si alguien se ha apoderado de él sin derecho alguno (EXP. N.o 0008-2003-AI/TC.F.J.26) ${ }^{76}$.

Garantizar los derechos de propiedad es indispensable para el desarrollo económico. Sin ella, los agentes económicos no tendrían incentivo alguno para adquirir propiedades e invertir en ellas, pues correría el riesgo de perderlas.

$>$ Presupuesto equilibrado. La administración económica y financiera del Estado se rige por el presupuesto que anualmente aprueba el Congreso (artículo 770). El Presidente de la República envía al Congreso el proyecto de ley de presupuesto dentro de un plazo que vence el 30 de agosto de cada año.

74 El servicio público es el conjunto de prestaciones que buscan asegurar la satisfacción de las necesidades colectivas de interés general sujeta a un régimen de derecho público y a una regulación específica.

75 La Constitución de 1979 disponía adicionalmente la causal de interés social para efectuar alguna expropiación; sin embargo, dentro de la indemnización no se incluye el eventual perjuicio (artículo 125\%).

76 La propiedad no es un derecho absoluto, por ello, el derecho a la propiedad debe ser interpretado no sólo a partir del artículo $2^{\circ}$, incisos 8 ) y 16), sino también del artículo $70^{\circ}$, el cual establece que éste se ejerce en armonía con el bien común y dentro de los límites de la ley. 
Se fija expresamente que el presupuesto debe estar efectivamente equilibrado y que los préstamos procedentes del BCRP o del Banco de la Nación no se contabilizan como ingreso fiscal. Asimismo, no pueden cubrirse con empréstitos los gastos de carácter permanente (artículo $\left.78^{\circ}\right)$.

En esa orientación, este artículo es clave para el cumplimiento de la disciplina fiscal, que significa mantener los ingresos y gastos públicos en equilibrio (presupuesto equilibrado). El gobierno de un país que no cumpla con esta regla o práctica debe hacerlo sólo por medio de endeudamiento (interno y externo), considerando que éste tiene un límite a partir del cual, se presentan problemas económicos con consecuencias graves. Sin embargo, nuestra realidad económica nos ha permitido evidenciar que durante la década de los ochenta se imprimía billetes en forma desmesurada generando una hiperinflación ${ }^{77}$.

Legalidad de la ejecución del presupuesto. La Contraloría General de la República es una entidad descentralizada de Derecho Público que goza de autonomía conforme a su ley orgánica. Es el órgano superior del Sistema Nacional de Control. Supervisa la legalidad de la ejecución del Presupuesto del Estado, de las operaciones de la deuda pública y de los actos de las instituciones sujetas a control (artículo $\left.82^{\circ}\right)$.
Diagrama N.o 37:

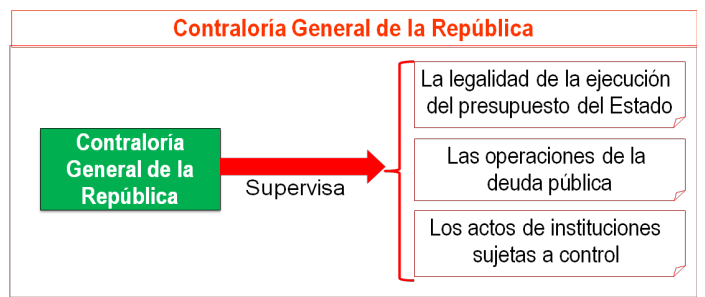

Para que los recursos del Estado se utilicen adecuadamente y honestamente es necesaria la existencia de un sistema de control del gasto y endeudamiento. La Contraloría General de la República es el órgano central de esta actividad de control y es conducida por el contralor general. El contralor viene a ser una especie de supremo fiscal del gasto público. El Contralor General es designado por el Congreso, a propuesta del Poder Ejecutivo, por siete años ${ }^{78}$. Puede ser removido por el Congreso por falta grave.

Limitación de congresistas para crear o aumentar el gasto público. Los representantes ante el Congreso no tienen iniciativa para crear ni aumentar gastos públicos, salvo en lo que se refiere a su presupuesto $\left(\text { artículo } 79^{\circ}\right)^{79}$.

En esa perspectiva, si se analizan las iniciativas legislativas se puede concluir que la gran mayoría de proyectos de ley conllevan, en mayor o menor medida, hacia algún tipo de gasto para el Estado. Sin embargo, consideramos que en este caso debe hacerse una interpretación restrictiva y no extensiva, ya que si se aplica este artículo a cabalidad, la gran mayoría de iniciativas legislativas devendrían en incons-

77 Un mayor gasto fiscal sin respaldo de los ingresos, tiende a reducir el crecimiento económico a largo plazo. Como consecuencia, para financiar el déficit, el gobierno probablemente tienda a aumentar los impuestos, afectando la actividad privada (efecto desplazamiento). Por ello, en el mundo es cada vez más frecuente el diseño y puesta en marcha de reglas fiscales claras imponiendo límites al déficit, gasto y deuda pública. En el mediano plazo se debe tender a un equilibrio fiscal.

78 El Ejecutivo es el órgano que efectúa el gasto y resulta contradictorio que sea éste quien proponga al Congreso. Asimismo, se requiere una mayor precisión en el sentido que la supervisión no sólo debe corresponder a la legalidad de la ejecución del presupuesto sino que debe incluirse en la Constitución el control de resultados de la gestión pública.

79 Este artículo carece de antecedente en la Constitución de 1979. 
titucionales. Por ello, el Congreso debería dar mayores precisiones al respecto o en todo caso definir un límite para los proyectos de ley.

Reserva de ley relativa en materia tributaria. El primer párrafo del artículo $74^{\circ}$ dispone que los tributos se crean, modifican o derogan, o se establece una exoneración, exclusivamente por ley o decreto legislativo en caso de delegación de facultades, salvo los aranceles y tasas, los cuales se regulan mediante decreto supremo ${ }^{80}$.

Los Gobiernos Regionales y Locales pueden crear, modificar y suprimir contribuciones y tasas, o exonerar de éstas, dentro de su jurisdicción, y con los límites que señala la ley.

Asimismo, el segundo párrafo del artículo $74^{\circ}$ dispone que el Estado, al ejercer la potestad tributaria, debe respetar principios siguientes ${ }^{81}$ :

1) Legalidad y reserva de ley tributaria. Para César Landa en materia tributaria, el principio de legalidad supone que el ejercicio de la potestad tributaria por parte del Poder Legislativo o del Poder Ejecutivo, debe estar sometida a la Constitución y no sólo a las leyes ${ }^{82}$. A diferencia de este principio, la reserva de ley significa que el ámbito de la creación, modificación, derogación o exoneración -entre otros- de tributos queda reservada para ser actuada mediante una ley.
2) Igualdad tributaria. El principio de igualdad denominado también capacidad contributiva consiste en tratar igual a los iguales y desigual a los desiguales, por lo que las cargas tributarias han de recaer, en principio, donde exista riqueza que pueda ser gravada, lo que evidentemente implica que se tenga en consideración la capacidad personal o patrimonial de los contribuyentes (EXP. N.o 2727-2002$\mathrm{AA} / \mathrm{TC})$.

El principio de igualdad tributaria se encuentra ligado al derecho a la igualdad contemplado en el artículo $2^{\circ}$ inciso 2 ) de la Constitución. En ese sentido, constitucionalmente, el derecho a la igualdad tiene dos facetas (EXP. N.o 0048-2004-AI/TC. F.J. 59 a 62):

a) Igualdad ante la ley. La norma debe ser aplicable por igual a todos los que se encuentren en la situación descrita en el supuesto de la norma.

b) Igualdad en la aplicación de la ley. Un mismo órgano no puede modificar arbitrariamente el sentido de sus decisiones en casos sustancialmente iguales, y que cuando el órgano en cuestión considere que debe apartarse de sus precedentes, tiene que ofrecer para ello una fundamentación suficiente y razonable.

3) Respeto de los derechos fundamentales de la persona (artículo $2^{\circ}$ de la Consti-

80 En materia tributaria existe la reserva de ley relativa, a diferencia del tratamiento de la propiedad donde la reserva de ley es absoluta. Relativa porque el artículo $74^{\circ}$ establece que los tributos se crean, modifican, derogan o exoneran exclusivamente por ley, sin embargo, luego dispone que también puede delegarse al Ejecutivo la creación, modificación, derogación o exoneración a través de decretos legislativos. Asimismo, los aranceles y tasas, se regulan mediante decreto supremo. De igual forma se exceptúan las contribuciones y tasas que crean, modifican y suprimen los Gobiernos Regionales y Locales.

81 La Constitución de 1979 reconocía además otros principios como el de justicia, uniformidad, obligatoriedad, publicidad, certeza y economía en la recaudación. No obstante, aunque no han sido incorporados siguen vigentes puesto que son garantías y fines del Derecho Tributario.

82 El Tribunal Constitucional en el EXP. N. ${ }^{\circ}$ 0489-2000-AA/TC ha establecido que el principio de legalidad abarca la determinación de todos los elementos que configuran un tributo (es decir: el supuesto de hecho, la base imponible, los sujetos de la relación tributaria "acreedor y deudor", el agente de retención y la percepción y alícuota), los cuales deben estar precisados o especificados en la norma legal, sin que sea necesaria la remisión "expresa o tácita” de un Reglamento o nomra de inferiro jerarquía (...). 
tución). Luigi Ferrajoli (2004: 37) sostiene que son derechos fundamentales todos aquellos derechos subjetivos que corresponden universalmente a "todos" los seres humanos en cuanto dotados del status de personas, de ciudadanos o personas con capacidad de obrar.

4) No confiscatoriedad. Significa que el tributo pagado sobre un bien no puede equivaler a todo el precio del bien, $\mathrm{o}$ a una parte apreciable de su valor.

Marcial Rubio (2008: 143) argumenta que confiscar es privar a una persona de su propiedad sin procedimiento debido ni pago previo de indemnización justipreciada. Esta definición del concepto proviene del artículo $70^{\circ}$ de la propia Constitución, en la parte que dice: A nadie puede privarse de su propiedad sino, exclusivamente, por causa de seguridad nacional o necesidad pública, declarada por ley, y previo pago en efectivo de indemnización justipreciada que incluya compensación por el eventual perjuicio.

De igual modo, las leyes de presupuesto y los decretos de urgencia no pueden contener normas sobre materia tributaria. Las leyes relativas a tributos de periodicidad anual rigen a partir del primero de enero del año siguiente a su promulgación. No surten efecto las normas tributarias dictadas en violación de lo que establece el artículo 74․

Cabe precisar que el artículo $118^{\circ}$, inciso 20) dispone que corresponde al Presidente de la República regular las tarifas arancelarias.

De acuerdo con Stiglitz (2000: 483) se acepta que un buen sistema tributario debe tener cinco propiedades:
Diagrama N.o 38:

Propiedades de un buen sistema tributario

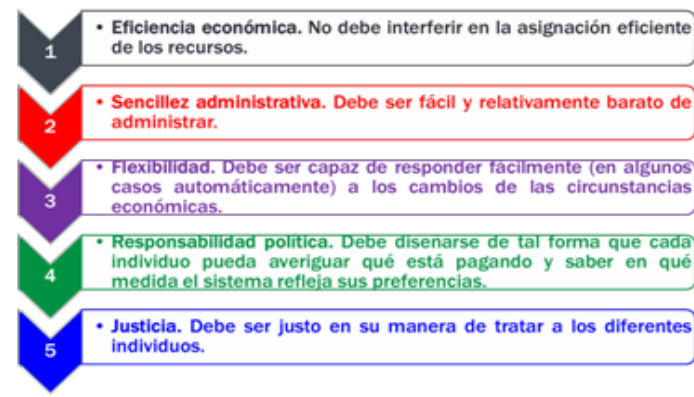

Ambiente y recursos naturales. Los recursos naturales, renovables y no renovables, son patrimonio de la Nación. El Estado es soberano en su aprovechamiento. Por ley orgánica se fijan las condiciones de su utilización y de su otorgamiento a particulares. La concesión ${ }^{83}$ otorga a su titular un derecho real, sujeto a dicha norma legal (artículo $\left.66^{\circ}\right)$.

Según el artículo $67^{\circ}$ el Estado determina la política nacional del ambiente. Promueve el uso sostenible de los recursos naturales. De acuerdo con Carlos Andaluz (2009: 52) el ambiente es el conjunto de elementos sociales, económicos, culturales, bióticos y abióticos que interactúan en un espacio y tiempo determinado; lo cual podría graficarse como la sumatoria de la naturaleza y las manifestaciones humanas en un lugar y tiempo concretos.

La segunda parte del artículo 2, inciso 22) dispone que toda persona tiene derecho a gozar de un ambiente equilibrado y adecuado al desarrollo de su vida. De acuerdo con el Tribunal Constitucional ${ }^{84}$ :

83 La concesión es el derecho que otorga una autoridad gubernamental a una persona natural o jurídica para desempeñar algunas funciones económicas. Según el EXP. N.o 0048-2004-AI/TC.F.J.108 la concesión minera: "( ... ) no es un contrato sino un acto administrativo, que determina una relación jurídica pública a través de la cual el Estado otorga, por un tiempo, la explotación de los recursos naturales, condicionada al respeto de los términos de la concesión y conservando la capacidad de intervención si la justifica el interés público".

84 Sentencia del Tribunal Constitucional EXP. $\mathrm{N}^{\circ}$ 0048-2004-AI/TC.F.J.17. Demanda de inconstitucionalidad interpuesta, en representación de más de cinco mil ciudadanos, contra los artículos $1^{\circ}, 2^{\circ}, 3^{\circ}, 4^{\circ}$ y $5^{\circ}$ de la Ley N. 28258 -Ley de Regalía Minera. 
El contenido del derecho fundamental a un medio ambiente equilibrado y adecuado para el desarrollo de la persona humana está determinado por los siguientes elementos: 1) el derecho a gozar de ese medio ambiente, 2) el derecho a que ese medio ambiente, se preserve.

En tal sentido, para lograr un ambiente sano, equilibrado y adecuado al desarrollo de la vida humana y que ese ambiente se preserve para las generaciones presentes $y$ futuras se requiere establecer prohibiciones o restricciones en la norma constitucional cuando exista un potencial daño al ambiente tal como lo dispone el artículo $72^{\circ}$, pero que no solamente se trate en caso de seguridad nacional.

$\mathrm{Al}$ respecto, es necesario tomar en consideración lo afirmado por Jeffrey Sachs (2008: 20), en el sentido que la actual trayectoria ecológica, demográfica y económica del mundo es insostenible, lo cual significa que, si continuamos haciendo las cosas como de costumbre, acabaremos padeciendo una crisis social y ecológica de consecuencias catastróficas.

Para Stiglitz (2010: 321) el crecimiento rápido que hemos alcanzado no es sostenible desde el punto de vista medioambiental ni social.

Régimen agrario y comunidades campesinas. El Estado apoya preferentemente el desarrollo agrario. Garantiza el derecho de propiedad sobre la tierra, en forma privada o comunal o en cualquiera otra forma asociativa. La ley puede fijar los límites y la extensión de la tierra según las peculiaridades de cada zona (artículo 88º).
Las tierras abandonadas, según previsión legal, pasan al dominio del Estado para su adjudicación en venta ${ }^{85}$.

En la cultura indígena existe una relación especial entre la tierra y el hombre, pues ambos son parte de la naturaleza. Esta relación profunda y peculiar con la tierra, que incluye a los recursos naturales, tiene dimensiones y componentes de carácter cultural, social, espiritual, etc. La tierra es algo más que una fuente de recursos y la relación que establecen con ella es uno de los elementos que mejor caracterizan la identidad indígena.

El artículo $6^{\circ}$ del Convenio 169 OIT dispone que "Al Aplicar las disposiciones del presente Convenio, los gobiernos deberán:

a) Consultar a los pueblos interesados, mediante procedimientos apropiados y en particular a través de sus instituciones representativas, cada vez que se prevean medidas legislativas o administrativas susceptibles de afectarles directamente (...).

b) Las consultas llevadas a cabo en aplicación de este Convenio deberán efectuarse de buena fe y de una manera apropiada a las circunstancias, con la finalidad de llegar a un acuerdo o lograr el consentimiento acerca de las medidas propuestas".

El artículo $13^{\circ}$ del Convenio 169 OIT establece lo siguiente: “ (...) los gobiernos deberán respetar la importancia especial que para las culturas y valores espirituales de los pueblos interesados reviste su relación con las tierras o territorios". En esa misma orientación el artículo $14^{\circ}$ dispone que:

1) Deberá reconocerse a los pueblos interesados el derecho de propiedad y de posesión sobre las tierras que tradicionalmente ocupan $(\ldots)$.

85 El artículo $89^{\circ}$ establece que las comunidades campesinas y las nativas tienen existencia legal y son personas jurídicas. Son autónomas en su organización, en el trabajo comunal y en el uso y la libre disposición de sus tierras, así como lo económico y administrativo, dentro del marco que la ley establece. La propiedad de sus tierras es imprescriptible, salvo en el caso de abandono. Asimismo, se dispone que el Estado respeta la identidad cultural de las comunidades campesinas y nativas. 
2) Los gobiernos deberán tomar las medidas que sean necesarias para determinar las tierras que los pueblos interesados ocupan tradicionalmente y garantizar la protección efectiva de sus derechos de propiedad y posesión.

3) Deberán instituirse procedimientos adecuados en el marco del sistema jurídico nacional para solucionar las reivindicaciones de tierras formuladas por los pueblos interesados.

Bajo el mismo enfoque el Tribunal Constitucional mediante STC N.o 00024-2009$\mathrm{PI} / \mathrm{TC}$ ha señalado que "La propiedad comunal de los pueblos indígenas no puede fundamentarse en el enfoque clásico de propiedad sobre el que se basa el Derecho Civil. Para los pueblos indígenas la tierra no constituye un mero bien económico, sino un elemento fundamental con componentes de carácter espiritual, cultural, social, etc".

En otra sentencia (STC N. $00022-2009$ PI/TC) ha considerado que es cierto que cuando un pueblo indígena se ve perjudicado por la expropiación de su territorio se puede vulnerar algo más que su derecho fundamental a la propiedad. Se pone en riesgo también la propia existencia del pueblo indígena y sus valores espirituales. Es por ello, que la obligación del Estado no debe remitirse al pago de un justiprecio, sino que debe ir más allá, hacia un beneficio compartido. No basta pues con que se les otorgue nuevas tierras de igual extensión y calidad, sino que los pueblos indígenas deben beneficiarse de la explotación que se lleva a cabo en sus territorios ancestrales originales de los que fueron separados, garantizando con ello no solo la continuidad de su existencia sino el mejoramiento de la calidad de vida. Solo así puede comprenderse justificada la expropiación de tierras indí- genas, de lo contrario, los miembros de tales pueblos podrán recurrir a las vías legales pertinentes a fin de tutelar sus derechos.

\subsection{EVOLUCIÓN DE LA ECONO-} MÍA PERUANA: 1980-2011

Según Carlos Boloña ${ }^{86}$, a inicios de los noventa se llevaron a cabo reformas estructurales en nuestro país, que se dieron en tres grandes olas:

$>$ La primera ola de reformas se inició el 12/03/1991 y duró hasta abril del mismo año. Se aprobaron 61 decretos supremos sobre reducción de aranceles, liberalización del mercado cambiario, eliminación de monopolios públicos, liberalización del mercado laboral y se dio la primera norma de privatización de empresas públicas.

$>$ La segunda se dio entre el 18/05 y 15/11/1991. Se aprobaron 117 decretos legislativos al amparo de la delegación de facultades.

$>$ La tercera tuvo lugar entre el 5/04 y el 30/12/1992. Se expidieron 745 decretosley, 281 de ellos en diciembre. Estas se orientaron al sector comercio, sector financiero, sector público, sectores productivos, sectores sociales y al establecimiento del Estado de Derecho.

Durante el período 1988-1990, el PBI cayó de S/. 99,839.3 nuevos soles a S/. 82,032.2 nuevos soles, representando -17.8\%. En 1993, el PBI registró S/. 87,375 millones de nuevos soles y a partir de este año comienza a crecer hasta el 2011, alcanzando los S/. 224,669 millones de nuevos soles, con excepción de 1998, que cae ligeramente en $-0.7 \%$. Tal como se aprecia en el gráfico siguiente, en términos reales, el PBI creció durante el período 1993-2011 aproximadamente en $157 \%$.

86 Obra citada, páginas 55-7. 
Gráfico N.o 01:

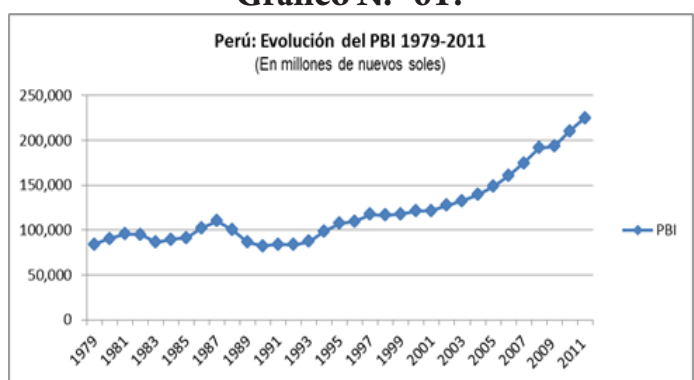

Fuente: Banco Central de Reserva del Perú

La inflación, pasó de $1,722 \%$ en 1988 a 7,649\% en 1990. Durante el período 19911993, la inflación alcanzó niveles del 139.2\%, $56.7 \%$ y $39.5 \%$, respectivamente. Para el 2011 la inflación fue de $4.7 \%$. Es importante resaltar que desde 1997 a la actualidad, la inflación no supera los dos dígitos y que el BCRP ha mantenido la autonomía que consagra nuestra Constitución, permitiendo que la política monetaria se maneje con un criterio técnico y no se encuentre sujeto a presiones de los gobiernos de turno. Sin embargo, debido a la inestabilidad política de nuestro país se requiere que la ratificación de sus miembros no esté condicionada a la política.

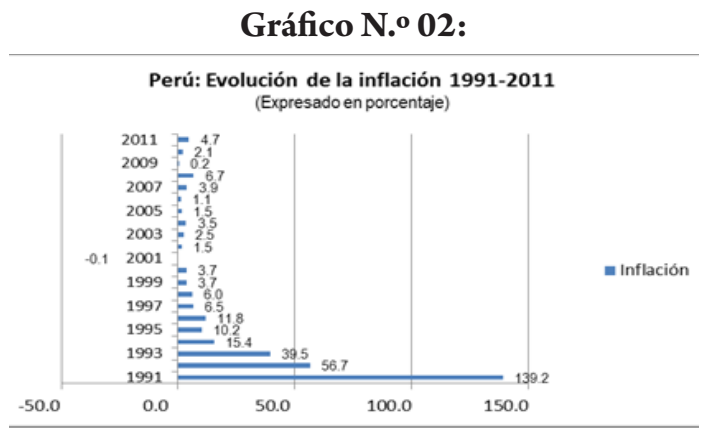

Fuente: Banco Central de Reserva del Perú
Hasta antes de 1990, se llevaron a cabo políticas inconsistentes: políticas fiscales expansivas acompañadas de políticas monetarias acomodativas mediante créditos del BCRP al sector público. Es así que, el BCRP llevaba a cabo: 1) operaciones cambiarias sujetas a un tipo de cambio fijo ${ }^{87}$, y 2 ) otorgamiento de créditos al gobierno y la banca de fomento. El único instrumento utilizado por el BCRP para compensar (sin éxito) la expansión monetaria fue incrementar la tasa encaje en moneda nacional ( $80 \%$ para julio de 1990).

En ese contexto, en agosto de 1990 se inició el programa de estabilización con la finalidad de detener la hiperinflación. La primera medida consistió en abandonar el sistema de tipo de cambio fijo e implementar un sistema de flotación sucia ${ }^{88}$. La segunda consistió en eliminar las fuentes de expansión de la emisión primaria, lo cual significó eliminar el financiamiento al gobierno (hecho que también se consagró en la Constitución de 1993, prohibiéndose al BCRP financiar al erario - artículo $84^{\circ}$ ) y a la banca de fomento. Esta situación permitió que en 1991 comience el ancla de base monetaria ${ }^{89}$. En consecuencia, el BCRP no volvió a financiar al sector público y se liquidó la banca de fomento, que fueron los principales factores que ocasionaron un aumento desmesurado de la emisión primaria, lo que generó elevados niveles de inflación ${ }^{90}$.

Asimismo, como parte de la política monetaria, se liberalizaron las tasas de interés, se dispuso la libre de tenencia de moneda ex-

87 Cuando el tipo de cambio es fijo, si sube (se pagará más unidades monetarias por un dólar) ocurre una devaluación de nuestra moneda con relación a la moneda extranjera y si baja ocurre una revaluación.

88 Las intervenciones permanentes del BCRP en el mercado cambiario durante los últimos años ha originado que nuestro nivel de Reservas Internacionales Netas al 31/12/2011 alcancen US\$ 48,816 millones de dólares, de los cuales US\$33,300 millones corresponde a la posición de cambio.

89 Se denomina ancla monetaria a la utilización del agregado monetario más importante: la base monetaria, como sustento de un programa de estabilización.

90 En los países latinoamericanos, el origen de las altas tasas inflacionarias se puede encontrar en los grandes y persistentes déficit fiscales que el banco central monetiza, es decir, que se pagan imprimiendo billetes. 
tranjera (artículo $64^{\circ}$ de la Constitución) ${ }^{91}$ y se permitió el libre ingreso y salida de capitales.

Cabe precisar que, durante el período 1993-2011 nuestro PBI por habitante creció $99.10 \%$, lo cual representa una mejora relativa en el nivel de vida de la población.

\section{Gráfico N.o 03:}

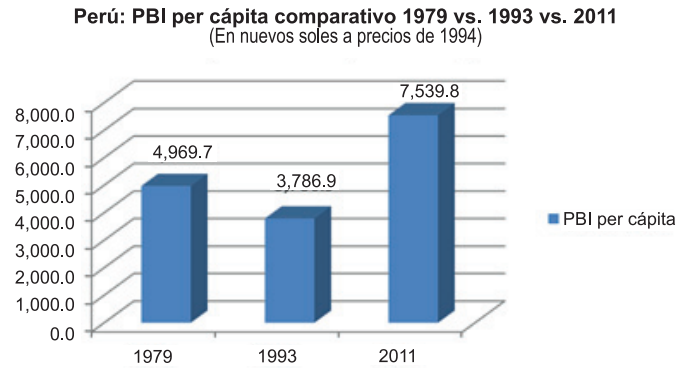

Fuente: Banco Central de Reserva del Perú

Tal como se aprecia en el gráfico siguiente, a partir del año 2002, nuestra balanza comercial registra un superávit de US\$ 321.1 millones de dólares, llegando el 2011 a situarse en US\$ 9,301.8 millones de dólares.

\section{Gráfico N.o 04:}

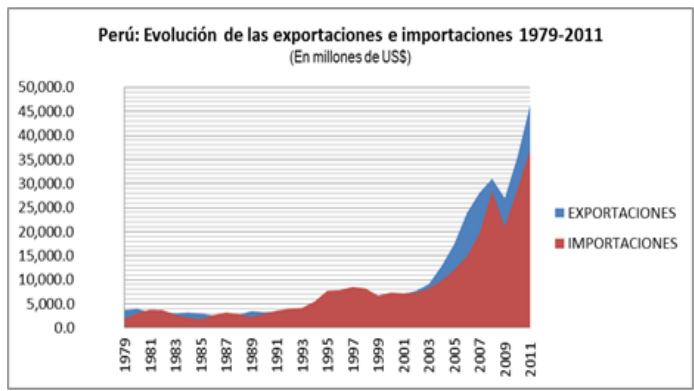

Fuente: Banco Central de Reserva del Perú

En términos generales durante los noventa, nuestro país se reformó. Sin embargo, lo que ha faltado son las reformas institucio- nales relacionadas con la reforma del Poder Judicial y la estabilidad al sistema político para impedir la corrupción y populismo.

Witker (2008: 32) sostiene que hoy en día predomina un nuevo sistema: el neoliberalismo, el cual no se opone "en principio a la intervención del Estado en la economía, sino sólo en casos concretos y particulares...”. Con este modelo, las críticas a las facultades de regulación económica por parte del poder público han acentuado la tesis de que el Derecho Económico, como disciplina está en vías de extinción; nada más distante de la realidad y pese a los esfuerzos privatistas y desregulatorios de los modelos vigentes, el Derecho Económico subsiste y se refuerza.

\section{CONCLUSIONES}

1) La Constitución Económica es el conjunto de reglas de juego claras en materia económica, con rango constitucional, que contribuyen positivamente en el desempeño económico de un país. Un aspecto trascendente de la regulación de aspectos económicos en la Carta Magna es que ésta no puede ser reformada por el procedimiento legislativo ordinario, razón por la cual constituyen un factor fundamental de la gobernabilidad de un país para un determinado tiempo de su devenir histórico. Si las normas constitucionales de carácter económico pudieran reformarse con la sencillez de una ley, las constituciones serían básicamente leyes.

2) Existe una relación muy estrecha entre la Constitución Económica y el desempeño económico de un país, ya que un Estado que no establezca claramente las

91 A finales de 1985 se estableció en nuestro país el dólar MUC (Mercado Único de Cambios), que consistió en la centralización de la negociación del dólar. El dólar MUC era negociado a un precio más accesible, ya que era subsidiado por el Estado. Considerado uno de los peores errores del primer gobierno de Alan García, porque generó mucha corrupción en el Estado, beneficiando a los grupos cercanos a los políticos de la época. 
grandes reglas de juego en materia económica no puede garantizar la estabilidad económica menos el crecimiento económico del país. Para tal efecto, se requiere garantizar el orden constitucional económico a través de órganos realmente independientes como el Tribunal Constitucional, el Poder Judicial, los Tribunales Administrativos (Tribunal Fiscal, Consejo de Minería, INDECOPI, Tribunal Registral, OSCE) que velen por el cumplimiento de la Constitución y las leyes.

3) La Constitución Política vigente se dio dentro del contexto de la caída del muro de Berlín (1989) y la desintegración de la URSS (1991), hechos que tuvieron como antecedente las recetas económicas implementadas en Gran Bretaña (1979) y Estados Unidos (1982), ambas fundamentadas en una economía de libre mercado. Asimismo, un aspecto trascendental para Latinoamérica fue el Consenso de Washington (1989), desde donde se estableció la agenda para la región.

4) La Constitución Económica de 1993 dispone la preservación de la estabilidad monetaria, prohibición del BCRP de financiar al erario, igualdad jurídica de la inversión, libertad de contratación, libre competencia, actuación subsidiaria del Estado, derechos de propiedad inviolable, libertad de trabajo, libertades de empresa comercio e industria; normas constitucionales que no pueden ser reformadas por el procedimiento legislativo ordinario, constituyendo un factor fundamental de la gobernabilidad y consiguientemente, se fijan las condiciones para el crecimiento económico. Por lo tanto, la Constitución Económica de 1993 así como las reformas implementadas han contribuido a indicadores económicos favorables: incremento del Producto Bruto Interno (PBI), control de la inflación, aumento del PBI per cápita, incremento significativo de la balanza comercial; asimismo, hay una posición superavitaria de las finanzas públicas y el nivel de Reservas Internacionales se ha incrementado considerablemente.

5) La Constitución Económica de 1993 se fundamenta en la Economía Social de Mercado o Estado Social de Derecho que asume los fundamentos del Estado de Derecho o liberal, pero además le imprime funciones de carácter social. Por lo que se sustenta en los principios esenciales de libertad dentro de la ley, seguridad, propiedad privada, soberanía, separación de las funciones supremas del Estado y reconocimiento de los derechos fundamentales. Principios que se deriva la igualdad ante la ley y el necesario reconocimiento de que el desarrollo del país se realiza en el marco de una Economía Social de Mercado. Las actuales reglas de juego en materia económica han contribuido a indicadores económicos favorables ya que nuestra economía a partir de su promulgación viene creciendo sostenidamente en el tiempo. Es así que el ingreso per cápita subió de $S /$. 3,786.9 nuevos soles en 1993 a $S / .7,539.8$ nuevos soles en el 2011. Del mismo modo, la inflación pasó de $39.5 \%$ en 1993 a 4.7\% en el 2011. 


\section{REFERENCIAS BIBLIOGRÀFICAS}

1. ACOSTA, Vicente 2003 "La Constitución Económica en el Perú". Tesis doctoral. Universidad Nacional Mayor de San Marcos

2. ANDALUZ, Carlos 2009 Manual de Derecho Ambiental. Lima. Editorial Iustitia.

3. AYALA, José 2004 Instituciones y Economía. México. Fondo de Cultura Económica.

4. BARKER, Greg (guionista) 2002 Commanding Heights: The Battle for the World Economy / Batalla por la economía mundial. Documental. Directores: Greg Barker y William Cran.

5. BOLOÑA, Carlos 1995 Cambio de Rumbo. Lima. Publicación del Instituto de Economía de Libre Mercado.

6. CAIRO, Omar 1998 "El constitucionalismo económico y social: trayectoria y actualidad". En: Enlace No 3. Revista de Sociología Jurídica. pp. 168 y ss.

7. CHANAMÉ, Raúl 2009 Comentarios a la Constitución. Lima. Jurista Editores E.I.R.L.

8. DALLA VIA, Alberto 1999 Derecho Constitucional Económico. Buenos Aires. Abeledo Perrot.

9. FRIEDMAN, Milton 1992 La Economía Monetarista. Barcelona. Editorial Gedisa S.A.

10. GARCÍA, Domingo 1993 Teoría y Práctica de la Constitución Peruana. Tomo 2. Lima. Ediciones Justo Valenzuela.

11. GARCÍA, Domingo y Walter GUTIÉRREZ 1993 Las Constituciones del Perú. Lima. Edición Oficial Ministerio de Justicia.

12. GARCÍA, Víctor 2008 Teoría del Estado y Derecho Constitucional. Segunda edición. Lima. Palestra Editores.

13. GUZMÁN, Christian 2009 Introducción al Derecho Público Económico. Lima. Ediciones Caballero Bustamante.

14. HAYEK, Friedrich A. 1978 Camino de servidumbre. Primera edición en libro de bolsi- 1lo. Madrid. Alianza Editorial S. A.

15. KEYNES, John M. 2003 Teoría General de la ocupación, el interés y el dinero. Cuarta edición en español. Fondo de Cultura Económica

16. KRESALJA, Baldo y César OCHOA 2009 Derecho Constitucional Económico. Lima. Fondo Editorial Pontificia Universidad Católica del Perú.

17. KRUGMAN, Paul 2009 De vuelta a la economía de la gran depresión y la crisis del 2008. Colombia. Grupo Editorial Norma S.A.

18. LANDA, César (Coordinador) 2008 Constitución Económica del Perú. Lima. Palestra Editores SAC

19. LANDA, César y Ana VELAZCO 2009 CONSTITUCIÓN POLÍTICA DEL PERU 1993. Octava edición. Lima. Fondo Editorial Pontificia Universidad Católica del Perú.

20. NORTH, Douglass $2007 \quad$ Para entender el proceso de cambio económico. Colombia. Editorial Norma S.A. 1993 Instituciones, cambio institucional y desempeño económico. Primera edición en español. México. Fondo de Cultura Económica.

21. RICHMAN, Sheldon s.f. Frédéric Bastiat - Una bibliografía anotada. En: Todo sobre Fréderic Bastiat. Fecha de consulta: 07/10/2011. <http://bastiat.org/es/bibliografia.html\# afiliacion>

22. RODRIK, Dani 2011 Una economía, muchas recetas. Primera edición en español. México. Editorial Fondo de Cultura Económica.

23. ROLL, Eric 1994 Historia de las doctrinas económicas. Tercera edición en españo. México. Fondo de Cultura Económica.

24. RUBIO, Marcial 2008 La interpretación de la Constitución según el Tribunal Constitucional. Segunda edición. Lima. Fondo Editorial de la Pontificia Universidad Católica del Perú. 
25. SACHS, Jeffrey 2008 Economía para un planeta abarrotado. Buenos Aires. Editorial Sudamericana S.A.

26. SACHS, Jeffrey y Felipe LARRAÍN 1994 Macroeconomía en la Economía Global. México. Editorial Prentice Hall Hispanoamericana S.A.

27. SCHMITT, Carl 1982 Teoría de la Constitución. España. Alianza Editorial.

28. SOLA, Juan Vicente 2004 Constitución y Economía. Buenos Aires. Editorial Abeledo Perrot.

29. STIGLITZ, Joseph E. 2010 Caída libre. México. Santillana Ediciones Generales. 2008 El malestar de la globalización. España. Santillana Ediciones Generales. 2003 Los felices 90. La semilla de la destrucción. Buenos Aires. Santillana Ediciones Generales.

2000 La Economía del Sector Público. España. Antoni Bosch, editor S.A.
30. TORRES Y TORRES, Carlos $1994 \mathrm{La}$ Constitución económica en el Perú. Lima. Desarrollo y Paz Editores.

31. TRIBUNAL CONSTITUCIONAL 2002 EXP. N.o 0010-2002-AI/TC. 2003 EXP. N.o 0261-2003-AA/TC. 2003 EXP. N. 0008-2003-AI/TC. 2004 EXP. N.o 3330-2004-AA/TC. 2004 EXP. $N^{\circ}$ 0048-2004-AI/TC. 2009 EXP. N.o 00022-2009-PI/TC 2009 EXP. N.o 00024-2009-PI/TC.

32. WIESE, Carol 2003 Reinventando el Estado: estrategia y cambio institucional en el Perú. Lima. Universidad del Pacífico.

33. WITKER, Jorge 2008Introducción al Derecho Económico. México. Editorial McGrawHill Interamericana Editores S.A. 